\author{
ECONOMIC GROWTH CENTER \\ YALE UNIVERSITY \\ P.O. Box 208629 \\ New Haven, CT 06520-8269 \\ http://www.econ.yale.edu/ egcenter/
}

CENTER DISCUSSION PAPER NO. 954

\title{
Population Policies, Fertility, Women's Human Capital, and Child Quality
}

\author{
T. Paul Schultz \\ Yale University
}

May 2007

Notes: Center discussion papers are preliminary materials circulated to stimulate discussion and critical comments

Support of the MacArthur and Rockefeller Foundations are acknowledged, and the comments of Eric Edmonds, John Strauss and other participants at the Conference on Economic Development, at the Bellagio Center, Italy, May 2-6, 2005 and the editorial comments of Sarah Cattan are appreciated.

Forthcoming in the Handbook of Development Economics, Volume 4, edited by T. Paul Schultz and John Strauss, Amsterdam: North-Holland, Elsevier.

This paper can be downloaded without charge from the Social Science Research Network electronic library at: $\underline{\text { http://ssrn.com/abstract=985956 }}$

An index to papers in the Economic Growth Center Discussion Paper Series is located at: http://www.econ.yale.edu/ egcenter/research.htm 
Draft4: Comment Welcomed

paul.schultz@yale.edu

\title{
Population Policies, Fertility, Women’s Human Capital, and Child Quality
}

\author{
T. Paul Schultz \\ Revision April 4, 2007
}

\begin{abstract}
Population policies are defined here as voluntary programs which help people control their fertility and expect to improve their lives. There are few studies of the long-run effects of policyinduced changes in fertility on the welfare of women, such as policies that subsidize the diffusion and use of best practice birth control technologies. Evaluation of the consequences of such family planning programs almost never assess their long-run consequences, such as on labor supply, savings, or investment in the human capital of children, although they occasionally estimate the short-run association with the adoption of contraception or age-specific fertility. The dearth of long-run family planning experiments has led economists to consider instrumental variables as a substitute for policy interventions which not only determine variation in fertility but are arguably independent of the reproductive preferences of parents or unobserved constraints that might influence family life cycle behaviors. Using these instrumental variables to estimate the effect of this exogenous variation in fertility on family outcomes, economists discover these "cross effects" of fertility on family welfare outcomes tend to be substantially smaller in absolute magnitude than the OLS estimates of partial correlations referred to in the literature as evidence of the beneficial social externalities associated with the policies that reduce fertility. The paper summarizes critically the empirical literature on fertility and development and proposes an agenda for research on the topic.
\end{abstract}

Keywords: Consequences of Fertility Decline, Child Quality, Evaluation of Population Policies

JEL classifications: J13, J24, O15 


\section{Introduction ---Why Are Economists Interested in Fertility?}

The relationship of fertility to economic development is a controversial subject, which is viewed differently by various schools of economists. Malthus (1789) relies on the classical economics concept of diminishing returns to labor applied to a fixed supply of natural resources, such as agricultural land. If fertility contributes to population growth, it diminishes in the long run the marginal product of labor and thereby reduces wage rates, holding the supply of agricultural land constant. In Malthus' framework fertility is assumed to cause a negative 'externality' or impose a social cost on society, because private individuals ignore these social consequences of their decisions to marry earlier and have more children. Malthus implicitly assumes an aggregate production framework to link higher levels of fertility to reduced workers' welfare, and completes the feedback mechanism by allowing falling wages to discourage early (i.e. improvident) marriage and reduce the number of births women have, on average. This model of macroeconomic-demographic equilibrium accounts for some key aspects of the pre-industrial European experience (Lee, 1973; Schultz, 1981, 2002; Guinnane,1997; Bengtsson, 2004), but does not explain the events that followed the industrial revolution when population growth paralleled economic growth in per capita terms.

In the two decades following the Second World War, high levels of fertility emerged as a potential constraint on economic development, at least in low-income countries. Population growth increased in these poor countries from 0.5 percent per year in 1900 , to 1.2 percent by 1940, and doubled again to 2.5 percent by 1960 (Kuznets, 1966; United Nations, 2003). This increase in the rate of population growth, although due to improvements in health which reduced mortality rather than increased fertility, seemed likely to overwhelm the capacity to accumulate capital in these developing countries to employ productively their rapidly growing populations. If fertility in low-income countries declined as slowly and with as long a lag after mortality declined as in Europe and areas of European settlement, this Malthusian framework implied a demographic poverty trap could arise which would prevent economic development (Coale and Hoover, 1958; National Academy of Sciences, 1971). With further study, however, the evidence linking rapid population growth to slower economic development was not confirmed to be a major impediment to modern economic growth, except where it was very rapid and discouraged investments in health and schooling (National Research Council, 1986; Johnson, 1999). This conclusion does not contradict classical diminishing returns to population growth, but only suggests that technical change and behavioral responses are able to outweigh these Malthusian constraints on economic growth, as illustrated by the successes in Asia and Latin America.

A second macro framework economists use to assess the implications of the fertility decline in the demographic transition focuses on the consequences of resulting changes in the age composition of a national population, that occurs because of the demographic transition. Modigliani and Brumberg (1954) assume that in each period the marginal utility from consumption diminishes with increasing levels of consumption, and adults maximize a lifetime utility function which is the separable sum of each adult's discounted utility. These widely accepted assumptions imply that adults would save a larger proportion of their earnings during their most productive years, between say age 35 to 55 , in order to raise their consumption opportunities during their less productive old age. If birth cohorts follow this hypothesized life 
cycle consumption-smoothing savings behavior, changes in the age composition of nations would affect national savings rates, in the absence of secular growth in economic productivity. Bloom and Williamson (1998), among others, have argued that the increase in the proportion of the population age 35 and 55 in the East Asian countries after fertility began to decline from 1960 to 1980 explains the rise in their national savings rates from 1970 to 1990 . Although savings rates increased in the wake of the demographic transition in many East and South-East Asian countries, savings rates have also increased in countries where the demographic transition has been more gradual and thus the age composition has changed much less, such as India. Conversely, savings rates have stagnated in other regions, such as Latin America, which experienced a relatively rapid early demographic transition similar to that experienced in East Asia. Even the within country variation in Asia does not suggest a robust statistical relationship between the age composition and savings rates within countries (Schultz, 2004a). Moreover, studies of household surveys do not generally find the pronounced humped shaped lifecycle variation in savings rates in either high- or low-income countries, as plausibly postulated by Modigliani (Deaton and Paxon, 1997).

With these two macro economic frameworks attributing social benefits to a decline in fertility, micro economists have sought to understand the determinants and consequences of fertility as a family decision process. Data from household sample surveys are analyzed to test the implications of household consumption and production models (Becker, 1960, 1981; Mincer, 1963; T.W.Schultz, 1973; T.P. Schultz, 1981, 1997; Hotz et al, 1997). If fertility and family resource allocations are determined jointly and simultaneously within a lifetime household decision making framework, it is expected that unobserved economic constraints on the household and preferences of couples would impact fertility and other lifetime household behaviors. The correlations between fertility and these family lifetime outcomes would therefore represent biased estimates of any causal effects or externalities that might follow if population programs were to reduce the cost of birth control and thus reduce fertility voluntarily. Empirical evidence has accumulated to substantiate the view that fertility is subject to choice in most settings and is determined simultaneously with other lifetime family behaviors (Rosenzweig and Wolpin, 1980a, 1980b; Schultz 1981; Moffitt, 2005)

The challenge is to estimate how exogenous shocks to fertility, such as might be produced by a population program, would impact other household coordinated choices, such as the allocation of women's time and other lifetime resources among activities which parents view as complements to, or substitutes for, having more children. On this list of coordinated household behaviors is, of course, the mother's supply of time to the labor market (Mincer, 1963), life cycle savings for old age support, as well as the expenditures of parents on a variety of activities that increase the lifetime productivity of their children, or child human capital (Becker and Lewis, 1974). Nutrition, health care, schooling, and migration of children are the most salient and readily quantified of these family outcomes, and many of these investments in children are publicly subsidized and encouraged, because they are viewed as benefitting society. It is often hypothesized that children customarily provide parents with support and consumption insurance in old age, and parents might view these child services as a substitute for savings in the form of physical assets (e.g. Samuelson, 1958). Within a lifetime household demand and savings framework, the problem is to disentangle the effects of exogenous variation in fertility on other 
long term family outcomes and to identify and estimate these effects. To estimate these effects of fertility variation on family resource allocations, retrospective life cycle histories or panel household surveys would be useful, which describe families for a sufficient time to infer long term equilibrium consequences of fertility change. Moreover, the researcher must specify a credible "exclusion restriction", which typically takes the form of an observed instrumental variable representing an exogenous "treatment" that affects to a significant extent fertility, and has no other effect on the family's welfare outcome of interest, such as the woman's health, productivity, labor supply, and asset accumulations, and her children's human capital.

There are relatively few empirical studies, reviewed later in this paper, which assess how fertility declines that can be attributed to population policy treatments or other forces outside of the family's control, have contributed to the formation of more human capital in women and in children, or augmented family physical savings, and thereby reduced poverty in the current and future generations of the family and contributed to economic development. Without credible evidence at the household level of these "cross effects" of population programs on fertility and long term family welfare, some skepticism is understandable when causal interpretations are offered for empirical associations between fertility, age compositions, and family welfare across populations at the aggregate level. Cross-country regressions are notoriously difficult to interpret as causal relationships in this context, because mortality and fertility tend to be dominated by secular trends (Moffitt, 2005; Schultz, 2004b), and this paper will therefore focus only on empirical evidence derived from analyses of household level data.

Although fertility may not be confidently linked as a causal factor driving national savings or growth, there is a persistent cross-country inverse relationship between real income per adult (i.e. GDP in Purchasing Power Parity per potential worker) and the total fertility rate (TFR is defined as the sum of age-specific birth rates for women summed across all reproductive ages, 15 to 49 , in one time period). This inverse relationship has remained quite stable between 1960 and 2000 (as plotted in Figure 1), during which time the average TFR in this sample of 95 countries decreased by 39 percent while real income per adult increased by 88 percent. $^{1}$ Does this empirical regularity imply that fertility declines cause income to increase, or does causation operate in the opposite direction from economic growth to fertility decline? There is as yet no consensus on the answer to this question. However, promising directions for research are reviewed below, in which individuals and households in cross sectional and panel surveys are analyzed to recover insights from special situations where exogenous environmental variables, including the exposure of individuals to population policies, account for some of the variation in fertility. Opportunities for this research include well-designed social experiments, quasiexperiments stimulated by nature or human institutions, and carefully evaluated instrumental

${ }^{1}$ The slope of the linear fit of log GDP per adult and TFR is not significantly different in the two years at the 5 percent confidence level, but TFR has fallen more slowly than the log of GDP per adult, suggesting that the level of a fitted linear function has shifted upwards slightly. This shift in intercept is also not significantly different from zero. The stability of this empirical regularity should not be interpreted as an indication that the relationship is causal and constant over time, but rather is a surprising outcome possibly caused by different changes in both fertility supply and demand (Rosenzweig and Schultz, 1985; Schultz, 1995). 
variable strategies that are shown to have both power and validity. The second stage in this research methodology is then to link this "exogenous" variation in fertility to long term "cross effects" in the household of these women and their families. These cross effects may eventually provide a more precise assessment of the spillover effects on development of specific population programs, such as family planning, child health and reproductive health programs, as well as provide a basis for explaining how the economic and social structure of development affects fertility. $^{2}$

In this chapter section 2 describes the potential consequences of fertility and health changes for individual and family well being. Section 3 outlines the policies which may change fertility and mortality and thereby contribute to the demographic transition. Section 4 summarizes a household life cycle demand model to illustrate how reduced form equations might be conceptually derived, and how identification is achieved to estimate structural relationships, such as the "cross effects" of policy-induced changes in fertility on long-term family outcomes. Empirical studies which have estimated the effects of specific exogenous sources of variation in fertility or population programs on family outcomes are surveyed in Section 5, concluding with a discussion of evaluations of the Matlab family planning program in rural Bangladesh, for which an experimental program has been followed for two decades. Section 6 draws some tentative generalizations from this survey, and reviews an agenda for further research.

\section{Long Term Effects of Fertility for Individuals and Families : A Micro Perspective}

There are many potential mechanisms at the family level which could link the declines in mortality and fertility associated with the demographic transition to household resource reallocations and improvements in the welfare of women, children, and men. These linkages between production and consumption in the extended family unfold over an extended period of time, during which children are a long term responsibility of parents, after which children may customarily become care-givers for their elderly parents. Table 1 outlines how fertility may exert an influence over long term family choices and living arrangements, and thus categorizes the many "cross effects" from fertility that one could imagine estimating.

One hypothesis is that human capital formation is affected by changes in fertility and mortality. Maternal mortality per birth is many times higher in many low-income countries in Africa and South Asia than it is in middle and high income countries. The decline in fertility would thus be associated in these low income regions with fewer risks of maternal mortality. Acute and chronic health problems of women may also be reduced, especially if birth control substitutes for unsanitary and high risk abortion, and achieves a healthier spacing of births for the

${ }^{2}$ The "cross effects" of fertility on family life cycle decisions and outcomes that are emphasized in this paper are not viewed as conditional demand effects, of for example, inflexible allocation shocks to the quantity of children on child quality. Conditional demand functions assume separable utility and are useful for interpreting short-run consumer behavior where "fixed commitments prevent instantaneous adjustment to the long run equilibrium and to the study of consumer behavior under rationing" (Pollak, 1969). In this paper the goal is to estimate the long-run equilibrium family response to changing prices of birth control (family planning programs) and fertility, although there are relatively few examples of such research. 
mother. However, correlations between fertility and family outcomes such as women's health, do not denote causation, without developing a compelling strategy for identification of this "cross effect" within the family.

Adolescent and young women may be able to stay in school longer because they do not become pregnant, and programs which inform youth of contraceptive options and the likely consequences of their behavior may delay childbearing. Once they leave school, women who have fewer children may accumulate more training and vocational experience outside of the home, which may be associated with increased productivity in the market labor force and enhanced wages over their remaining lives, as well as the ability to bargain more effectively over the allocation of household resources (Lloyd, 2005). However, few studies show how population programs lower fertility and thereby affect the vocational experience of women which would raise their wages (Table $1, \mathrm{I}$ B).

Some instrumental variable (IV) studies reviewed later provide a basis for conjecturing the magnitude of such a mechanism from exogenous fertility change to women's accumulation of human capital and earnings capacity in later life. However, these IV studies are not yet an adequate basis for generalization, because the scope for women to work in the labor force and outside of their family varies greatly across cultures and over time. Women who are relieved of the responsibility of bearing and rearing more unwanted children may be more likely to engage in self-employment activities which add to family resources and increase the opportunity value of women's time to other household activities. Women released from child care responsibilities may also increase their participation in women's groups, including microfinance organizations, and thus acquire productive assets to enhance their business opportunities. Decision making in the community and participation in local government may also evolve as women gain the capacity to regulate the timing and number of their births.

The effect of fertility decline may also take the form of intergenerational transfers, associated most often with child human capital in nutrition and health (Table 1, I C), schooling (I D), migration ( 1 E) and perhaps delay of a daughter's marriage ( I F ) (Field and Ambrus, 2005). To these studies should be added investigations of inter vivos gifts and bequests from parents to children to complete the accounting of intergenerational transfers (Becker, 1981). These various forms of child human capital and financial transfers may also have reinforcing returns, at least in some settings (Schultz, 2001). The link of fertility to child migration is perhaps the least well studied, and most analyses of inter-generational effects of fertility on child human capital treat fertility as not being a choice variable which embody the multiple effects of preferences and unobserved heterogeneity. Therefore, the associations reported in the literature are generally incorrectly viewed as causal effects of the number of siblings (parent fertility) on human capital and economic performance, and only rarely is fertility treated more appropriately as endogenous and identified by an valid instrument (Black, et al., 2005a,b).

In a growing number of low income countries legislated transfer programs are being introduced which are conditional on investments being made in child human capital. In Bangladesh a conditional transfer program made payments to a girl's bank account, if she enrolled in secondary school and did not get married before the legal age of 18 (Arends-Kuenning and Amin, 2004). Although increasing women's schooling appears to increase her wage 
opportunities, a delay in her marriage may be privately costly for her parents. Field and Ambrus, (2005) find in rural Bangladesh that delaying a daughters marriage beyond the age of menarche when she commands the best prospects in the marriage market contributes to an increase in the dowry the parents are required to pay, even if the daughter who is now older has completed more schooling. It is also unclear whether the wage returns a daughter might potentially earn due to attending more school are recovered by her parents, even if she takes a job before marriage (Quisumbing and Maluccio, 2003). As noted later, an experimental family planning program in Matlab Bangladesh reduced fertility, but was not associated with increasing the age when women exposed to the program had their first birth, although the woman's sons tend to eventually receive more schooling and have fewer siblings (Joshi and Schultz, 2007).

The second broad area of family resource allocation which is likely to be sensitive to fertility is the family's allocation of time, and specifically the woman's supply of time to work outside of the family (Table 1, II A). When they reduce their fertility, women tend to allocate more of their time to activities other than child care, and if the employment opportunities outside of the family are more attractive than those within the family, a program induced decline in fertility is likely to be associated with an increase in labor force participation and an increase in hours worked. If the market employment opportunities for women were unattractive, she may allocate more time to home production and self-employment activities. But as emphasized before, these correlations of fertility with different allocations of labor within the family are not a reliable measure of a causal effect, nor should it be assumed that by women working in any specific set of activities women's welfare will necessarily improve.

The probability that children will work in the labor force and the number of hours they so work could also be impacted by a policy-induced decline in their mother's fertility ( II B). One might hypothesize that mothers who have reduced their fertility are more likely to send their children to school, and this may reduce the time available for the children to work. Yet, the connection between the increase in school enrollment induced by a random village allocation of the Mexican Progresa Program's conditional cash transfers for enrollment had a relatively small effect of reducing the reported level of child labor (Schultz, 2004a). ${ }^{3}$

Models in which the labor supply of all family members are potentially coordinated find the expected interdependency of the time allocation of all family members, not only within the nuclear and intergenerational family, but also within the household and perhaps the residential compounds of the extended family e.g. the Bari in Bangladesh. In high income countries, the effect on the market labor supply of the husband of an increase in his wife's wage tends to be negative (uncompensated for the implicit income effect) but generally small and imprecisely estimated. In contrast, the effect on the wife's labor supply of an increase in her husband's wage

${ }^{3}$ It should be stressed that child labor is not easily measured in a household survey in a low-income country, because children generally work with their parents, without receiving formal payment, and are therefore not customarily viewed by parents as "workers" despite their contribution to family income. Work and schooling do not exhaust the time of children, and children are able to work without apparently reducing their schooling or subsequent earnings, although this is likely to depend on many other factors. See E. Edmonds chapter of this volume. 
tends to be negative and relatively large in most studies of family labor supply (Killingsworth, 1983; Schultz, 1981).

The life cycle model of savings assumes that children do not influence wealth accumulation, and the ratio of savings out of disposable income follows a regular profile with respect to the adult's age. Individuals accumulate sufficient wealth to smooth their consumption during their old age when their productivity declines (Modigliani and Brumberg, 1954). It is perhaps more plausible to assume parents are motivated to have children in part by the expectation that their children would support and care for them in old age (Samuelson, 1958). A policy-induced reduction in fertility could motivate parents to substitute more of their resources into savings to replace the support they had previously expected to receive from children. Although national accounts define savings as only the accumulation of nonhuman capital, parents may also increase their children's human capital as an alternative form of life cycle savings. Few studies report the association between conventional savings and fertility of parents (Hammer, 1986), and I could not find a single study estimating the savings effects of a policy-induced change in fertility. As with the Rosenzweig-Wolpin (1980b) model of fertility and female labor supply, I would expect parent relative preferences for childbearing as a means to smooth lifecycle consumption might be inversely related to the preferences for other forms of their physical savings, across a population with heterogeneous preferences. Estimates of fertility "cross effects" on savings based on exogenous shocks to fertility might then be expected to be smaller in absolute value than those implied by OLS estimates from a cross section in which fertility is assumed to be determined outside of the model and affect life cycle savings as an exogenous factor.

It is hypothesized that parents in reducing their fertility increase their transfers to each child in the form of gifts as well as human capital, motivated possibly by an increase in the returns for their support of schooling, health, and migration investments (e.g. Becker, 1981; Quisumbing and Maluccio, 2003). If physical savings, child human capital investments, and parent to child transfers are all substitutes for numbers of children, empirical studies are needed to document the degree of substitutability, and how they vary across cultural and institutional settings (Quisumbing, et al. 2004). The responsiveness of parents in this regard could be an important social rationale for population policies which achieve a voluntary reduction in fertility.

But the magnitude of such within family transfer relationships to the mother would be mediated by family structures and the customary obligations of children to their elderly parents, and weakened by the state's provision of pensions or medical care for the old and infirm. If the woman who has fewer children improves her own earnings capacities and she accumulates more over her life in physical assets through personal savings, she may have less need for income transfers from her offspring in old age. Whether inter-generational investments in child human capital lead to reciprocation in the form of child-to-parent transfers has not been extensively studied, where the source of variation in fertility is arguably exogenous. Because panel surveys rarely collect wealth, income, or consumption data from all related family units, currently it is hard to assess whether a transfer between parents and children is motivated by family altruism, strategic behavior, or family wealth maximization. 
A final consequence of fertility decline is on family living arrangements (Table 1, V). Since the $19^{\text {th }}$ century economists have studied the determinants of household expenditures and sought to control for the needs of the different households as summarized by their demographic composition, or the number of household members in various age and sex categories (Deaton, 1997). In studies of economic and demographic behavior, such as the family lifetime outcomes listed in Table 1, it is not plausible to assume that household composition and living arrangements are independent of changes in fertility, or that they are exogenous to human capital investments, time allocation, savings and transfers. These tenuous working assumptions underlying many studies of behavioral and productive relationships centered on the family and are likely to distort estimates of cause and effect relationships. Households form, divide, grow through births and inmigration, and decline through deaths and out-migration, partly in response to the key income, price and technology variables that are expected to account for household behavioral demands (Rosenzweig and Wolpin, 1985; Foster, 1998; Maluccio, et al, 2003; Hamoudi and Thomas, 2005). Thus, household composition should be treated as endogenous to studies of individual outcomes. The long standing convention in studies of family welfare of conditioning on household composition should thus be approached with caution, or at a minimum evaluated critically as a potential source of model mis-specification. If household composition adjusts to the opportunities created by a family planning program, which reduces the cost of birth control, then data on the extended family unit may need to be collected, and initial conditions should be specified to help explain the evolving composition of families (e.g. Akresh, 2004; Joshi, 2004; Hamoudi and Thomas, 2005; Ksoll, 2007).

\section{Policy Interventions in Family Planning, Child and Reproductive Health?}

Public policy interventions to promote the decline in mortality, morbidity, and fertility, are expected to benefit women and their families. Table 2 outlines five overlapping ways policy could contribute to declines in fertility. Because each may operate by different behavioral mechanisms and influence different groups, each is likely to cause different "cross effects" on other forms of family behavior and outcomes as listed in Table 1.

\subsection{Public Subsidies to Accelerate Diffusion of Beneficial Innovations}

First, public policies can subsidize sex education, information regarding best practice birth control methods, related supplies and medical services, and reproductive health programs with testing and treatment of various health problems including sexually transmitted diseases. Subsidies could directly reduce the cost of birth control, provided by either the private sector or by public delivery systems. The choice between private and public sector distribution could be determined in part to minimize social costs (psychic and monetary) and also to achieve a more equitable distribution of the private benefits of the program.

The initial adoption of birth control techniques may occur slowly, despite the existence of demand for reduced fertility. Heterogeneity in individual capacity to evaluate new opportunities may lead to behavioral lags which can be reduced by subsidies for related information, education, and supplies. Targeting the subsidies might be based on expected benefits, which could be approximated by the effectiveness of a subsidy to reduce birth rates. Alternatively, the subsidy could be targeted to achieve other distributional goals, such as reducing unsafe abortion or decreasing childbearing among teen-agers, or serving poor rural communities in which health and schooling services are otherwise sparse. 
Subsidies may be allotted so as to also be cost-effective in promoting voluntary adoption of new birth control techniques. Once adoption and use of modern birth control becomes widespread, general subsidies for their continued use may become a lower priority. By targeting the subsidy to those groups whose fertility continues to respond most strongly to a given price subsidy, the program can strive to maximize its effect on birth rates. Other program objectives could justify targeting specific segments of the population, such as lower income rural households, or teenagers, are other groups for which the health risks of unwanted childbearing are relatively high, assuming "unwantedness" can be suitably measured.

\subsection{Redistribution of Benefits within and between Families}

A second argument for public expenditures is to spread the voluntary use of birth control involves the consequences of improved birth control on the personal distribution of welfare within families, and specifically improvements in lifetime opportunities for women and their children. Intra-family distributional effects of population policies may be important and deserve more study using collective or bargaining models of the family (McElroy and Horney, 1981; Chiappori, 1992; Haddad, et al., 1997; Browning and Chiappori, 1998). The major initial technological innovations in birth control occurred in the 1960s with the refinement of the intra uterine device (IUD-Ota ring) and the discovery of the oral steroid (pill), which separated the practice of birth control from the act of sexual intercourse, and gave women a more independent role in the adoption and practice of birth control. Although it is not empirically well established, it is reasonable to presume that women are able to exercise greater control of their reproductive lives due to these new birth control technologies, and subsequent advances in birth control injections, implants, copper wrapped or drug coated IUDs, female condoms, laproscopic sterilization procedures,"menstrual regulation", abortion, and pills for pregnancy termination -have further added to options for women to control their reproduction.

These changes in birth control technology reduce uncertainties regarding when children are born and allow women to plan more confidently for their own education and careers, and thus optimize their lifetime productive opportunities, working either in the home or in the labor force. Society should gain from this wider access to "best practice" methods of birth control, which allows women to invest more efficiently in their market-oriented human capital. Women with an additional year of schooling receive wages which are proportionately higher than their less educated peers, and these private wage returns to schooling tend to be as high or higher for women as for men (Schultz, 1995). The diffusion and continued use of best practice birth control techniques should, therefore, motivate women to complete more schooling relative to men, other things being equal. These new birth control technologies may redistribute control of resources within families, and according to some empirical studies guided by the bargaining or collective models of the family, this should increase household expenditures on the nutrition, schooling, and health of children (Thomas, 1990, 1994; Browning 1992; Haddad, et al. 1997; Lam and Duryea, 1999; Schultz, 2001; Quisumbing and Maluccio, 2003).

When should health programs, such as family planning and reproductive health, be publicly subsidized, and for whom and by how much, raise distributional issues that cannot be dealt with in this paper. Evidence is accumulating to suggest that better early childhood nutrition and the prevention of inflammatory childhood diseases can increase childhood survival in the short run, and in the long run improve the children's health status as adults, as measured by 
reduced chronic illnesses and degenerative diseases and fewer functional limitations and disabilities (Barker, 2001; Finch and Crimmins, 2004; Fogel, 2004; Gluckman and Hanson, 2006).

\subsection{Conditional Transfers}

A third form of public intervention, noted earlier, involves conditional transfers to families, if families engage in high-return investments, typically in human capital. For example, Bangladesh introduced a secondary school scholarship program for girls, contingent on their not marrying before age 18. Mexico made transfers to poor mothers in rural marginalized areas (the PROGRESA program), if their children enroll in school and family members receive recommended vaccinations and preventive health care (Schultz, 2004a; Parker et al., in this volume). These targeted public subsidies require methodical planning, design of appropriate incentives, and careful monitoring to achieve their objectives. These conditional transfer programs offer a promising mechanism to alleviate poverty in the short run while encouraging longer run investments in the nutrition, health and schooling of poor children (Morely and Cody, 2003). Combined with effective targeting to the poor, conditional transfer programs may be more efficient in stimulating investment demand for human capital among the poor than conventional policies which increase public supply of expenditures, such as on education by constructing more schools, reducing class size, or paying higher teacher salaries.

\subsection{Women's Property Rights and Access to Credit}

Women's property rights to productive assets, inheritances, pensions, divorce and child custody are hypothesized to enhance both the welfare of women and possibly their children. If women are provided more bargaining power in the family, do their human capital capabilities increase, and does this enhanced economic value of women's time cause them to have fewer children and invest a greater amount in each child's human capital, holding constant the family's full income (Schultz, 2001; Quisumbing and Maluccio, 2003)? Where marketable title to land and other assets are insecure for women, and their land is vested in the hands of their husbands, women have greater difficulty borrowing to invest in their own enterprises. When they head their own households, they may be restricted to engage in home production activities, because of the need to protect their property rights (Field, 2003).

An objective of many micro finance programs is to help women overcome their traditional disadvantages in the credit market due to their lack of loan collateral and the customary interpretation of their property rights. Group joint liability arrangements for borrowing, encourage others in the group to monitor and enforce repayment of loans, in order for each participant to benefit in the future by access to the revolving credit. One prototype of this micro credit organization is the Grameen Bank of Bangladesh (Pitt and Khandkar , 1998). The design of legal systems and the practice of customary arrangements at the time of marriage may also affect bride prices and dowries, and may influence who actually controls the transfers at the time of marriage within the families, and who has custody of the children of that union, if it dissolves (Quisumbing, et al. 2004; Joshi, 2004; Field and Ambrus, 2005; Edlund and Lagerlof, 2006). Does the increased control of reproduction achieve for women greater economic independence outside of the family, and thereby contribute to their participation in the economy.

\subsection{Involuntary Population Policies which set Birth Quotas}


Population policies can either change the incentives and opportunities which lead people to voluntarily change their fertility, or it can set administrative limits on fertility, without compensating those who are then prevented from realizing their desired family size. Many of the welfare programs emphasized above which subsidize birth control, increase women's human capital, or strengthen their control of resources in the family, and are thus designed to affect fertility by changing the balance of private costs and benefits of having children, in other words, the income of women and men and the relative prices of children and other lifetime activities which are complements and substitutes for children.

China is alone in adopting a birth quota to reduce fertility and slow population growth. The costs of this policy differs across individuals, though it is difficult to identify who is disadvantaged and thus suffers a welfare loss because of the quota restriction. It is arguably the least educated, rural women (and men) who are most likely to be penalized by the quota, who tend to have the largest families in other similarly poor countries. Moreover, when fines are imposed for an "out-of-plan" birth, they appear to be fixed in monetary terms in China at the community level, and are therefore less of a disincentive to the rich than to the poor (Schutlz,2004c). Rationing theory implies that the magnitude of the "cross effect" from the rationed good to substitute goods will be larger (in the vicinity of the equilibrium amounts demanded) under the rationing regime than under a voluntary (family planning) regime where choice is affected only by subsidies and taxes (Tobin and Houthakker, 1950-1951; Pollak, 1969). Thus, if child schooling and physical life cycle savings are substitutes for children, cross effects of a population policy would be greater on these family outcomes with a birth quota than with a voluntary family planning regime which had equivalent effects on fertility. Thus, voluntary versus mandatory population policies, which might lead to the same decline in fertility, could theoretically have a different effect on other family outcomes and on the distribution of welfare losses and gains.

\section{A Conceptual Framework for Family Lifetime Fertility and Coordinated Decisions}

How do families respond to a reduction in the cost of birth control or an increase in access to more cost-effective forms of birth control? The avoidance of "unwanted births" increases the family's resources available for other activities, in other words it causes a lifetime gain in wealth. If the other activities are thought of as substitutes for the services children otherwise provide their parents, these substitute activities would receive a disproportionately larger share of these augmented family resources, and may improve the status of women and children and facilitate economic development. A simple economic framework may illustrate this idea.

Assume parents maximizes a separable two-period lifetime utility function, $\mathrm{V}$, that is the sum of the utility from their periods of (1) working adulthood and (2) retirement, in which the arguments in their unified family utility function are consumption in both period, $\mathrm{C}_{1}, \mathrm{C}_{2}$, leisure in the first period, L, number of children, $\mathrm{N}$, human capital per child or child quality, Q, and assets inherited in the first period, A. Parents may add savings in the first period (or draw down inherited assets) and thereby increase (or diminish) their consumption in the second period, when parents are unable to work. Parents could value A, N, and Q in the second period in part because they expect these selected variables to yield them a "return" as would an investment, $\mathrm{r}_{\mathrm{a}}, \mathrm{r}_{\mathrm{n}}, \mathrm{r}_{\mathrm{q}}$, respectively, while $\mathrm{N}$ and $\mathrm{Q}$ may also be enjoyed by parents as a form of pure consumption. 


$$
\mathrm{V}=\mathrm{U}_{1}\left(\mathrm{C}_{1}, \mathrm{~L}, \mathrm{~N}, \mathrm{Q}\right)+(\mathrm{l} /(1+\delta)) \mathrm{U}_{2}\left(\mathrm{C}_{2}, \mathrm{~N}, \mathrm{Q}\right)
$$

where $\delta$ is a discount rate for the second period of the life cycle. Parents have a fixed amount of time in the first period, $\mathrm{T}$, to allocate between working $\mathrm{H}$ hours for wage $\mathrm{w}$ or leisure(household production), $\mathrm{L}$, and income in the first period is exhausted by consumption and savings, $\mathrm{S}$ :

$$
\mathrm{Y}=\mathrm{Hw}+\mathrm{r}_{\mathrm{a}} \mathrm{A}=\mathrm{C}_{1}+\mathrm{S}
$$

where expenditures on children, $\mathrm{P}_{\mathrm{n}} \mathrm{N}$, and expenditures on child human capital, $\mathrm{P}_{\mathrm{q}} \mathrm{QN}$, are expressed in terms of the market prices of a child and child human capital, $\mathrm{P}_{\mathrm{n}}$ and $\mathrm{P}_{\mathrm{q}}$, respectively. Consumption in the terminal period, $\mathrm{C}_{2}$, is then the sum of returns on the three forms of assets parents can accumulate over their working period for their consumption during retirement: physical assets, children, and child human capital:

$$
\mathrm{C}_{2}=\mathrm{r}_{\mathrm{a}}(\mathrm{A}+\mathrm{S})+\mathrm{r}_{\mathrm{n}} \mathrm{P}_{\mathrm{n}} \mathrm{N}+\mathrm{r}_{\mathrm{q}} \mathrm{P}_{\mathrm{q}} \mathrm{QN}
$$

Ideally, empirical estimates would be identified of the "cross effects" of exogenous variation in fertility on the family's demand for child quality, savings, and leisure (or market labor supply): Q, S, and L (or H). Hypotheses are advanced regarding the sign of the cross derivatives of the effects of prices on various demands, holding income constant (i.e. income-compensated cross-effects are denoted here by *) : (1) children and child quality (i.e. human capital) are widely hypothesized to be substitutes for parents, in which case $\left(\mathrm{dV}^{2} / \mathrm{dN} \mathrm{dQ}\right) *<0$, and (2) a parallel hypothesis is that children and physical savings over the life cycle are also substitutes, i.e. $\left(\mathrm{dV}^{2} / \mathrm{dN} \mathrm{dS}\right)^{*}<0$, and finally (3) that nonmarket time or leisure and home production of the mother is a complement with the number of children she has, at least this is expected when children are young and in the household, $\left(\mathrm{dV}^{2} / \mathrm{dN} \mathrm{dL}\right)^{*}>0$. The cross derivatives of an exogenous change in fertility caused by exposure to the experimental family planning program on the demand for a commodity is negative if parents view children and that commodity as complements, or positive if children and that commodity are substitutes (Tobin and Houthakker, 1950-51; Rosenzweig and Wolpin, 1980a). Some assets may be more productive when parents have more children, as for example complementarity between child labor and farmland. Other types of assets such as a tube-well for drinking water in the homestead might function as a substitutes for child labor as well as women's labor in the family.

Statistical evidence is now needed on how the household portfolio of different types of assets adjusts to lower cost of birth control, which reduces fertility, and thereby exerts what is generally expected to be a positive substitution effect on the family's life cycle demand for physical assets and especially on those types of assets whose marginal product does not increase with child labor. There will also be a positive income effect due to the avoidance of unwanted and ill-timed births which raises the demand for all normal goods, which will include second period consumption as supported by the accumulation of household physical assets. The income effect will also tend to increase the demand for child quality (presumably a normal good). This positive income effect on quality of avoiding unwanted births could be erroneously interpreted as implying that the income-compensated cross-substitution effect is positive, and that child quantity and quality are substitutes. 
Child mortality, although less readily controlled by the family's resource allocation decisions and technology than fertility, may also be affected by the family's behavioral responses to its preferences and constraints, although child mortality is in this context often assumed to be exogenous (Schultz, 1981). The family's formation of child human capital, Q, in the form of nutrition and health care, may influence child mortality, as well as respond to the local availability of public and private health services, the general disease environment, and the child's genetic frailty. When a community public health program reduces the cost of birth control and introduces effective child and maternal health inputs, it may be difficult to recover from an empirical evaluation of the program's effects whether the consequence are of only the birth control subsidy component of the program, or a consequence of only the (child and maternal) health component of the program, or both. The theoretical implications of child survival for fertility are also more complex in a dynamic behavioral model with uncertainty, features of the life cycle decision making process which are neglected here (Ben Porath, 1976 ; Wolpin, 1997).

Reduced-form equations may be estimated for N, Q, s, and $\mathrm{H}$ in terms of all the exogenous variables in the model: $\mathrm{A}, \mathrm{w}$, the prices of $\mathrm{N}$ and $\mathrm{Q}$, and the financial returns in the market to $\mathrm{A}$, $\mathrm{N}$, and $\mathrm{Q}$. Unfortunately, many surveys provide little data on $\mathrm{Q}, \mathrm{S}, \mathrm{H}$, or returns on the three forms of family assets. The statistical errors in these reduced-form equations will tend to also be intercorrelated because they are jointly determined by unobserved parent preferences, family endowments, prices, or technological opportunities, and errors in optimization.

A key issue for empirical analysis is the specification and measurement of an instrumental variable which impacts fertility and yet is unrelated to the preferences or unobserved endowments and constraints affecting the family's other demands. In other words, the researcher must assume that an instrumental variable is uncorrelated with the errors in the reduced-form equations for the other family outcomes? ${ }^{4}$

The review of the empirical literature below in section 5 finds a variety of instrumental variables that researchers have treated are exogenous to the family lifetime decision making process, and that thus provide the critical basis for identifying and estimating the "cross effects" or the structural impacts of exogenous changes in fertility on another family outcome. A secondary issue is how widely the estimated "cross effect" would apply to represent the effect of different policy treatments, and to different changes in other family outcomes. The response to a decline in the price of birth control may in a stylized model be equated to the response of having twins, with the sign reversed (Rosenzweig and Wolpin, 1980a, 2000). But more realistically, the effect of a population program or exogenous event is likely to depend on the mechanism by which it impacts fertility, and to which subgroups in the population are influenced by the treatment. There is some reason to expect that the same instrumental variable could lead to different estimates of "cross effects" of a program-induced fertility decline in different circumstances, and

4 Various instrumental variables for fertility, such as the family planning program, could lead to different estimates of "cross effects" of a fertility decline in different circumstances. Our estimates are therefore not presented as a general pattern of response to this type of policy intervention, but as local average-estimates of the treatment effect (or intension to treat at say the village level) for a specified population (Imbens and Angrist, 1994). 
a goal of the paper is to assess whether existing regularities in the empirical literature are consistent with any generalizations (Imbens and Angrist, 1994).

\section{Empirical Studies of Fertility and the Consequences for Families}

This chapter does not review the extensive interdisciplinary literature reporting the direct associations between fertility and family outcomes (e.g. Becker, 1981; Blake; 1989; Hanushek, 1992; Lloyd, 1994; Desai, 1995). I concentrate instead on studies which estimate an explicitly causal model for fertility and another family outcome, in which both outcomes are allowed to be jointly and simultaneously determinated. These investigations often report both the direct (OLS or Probit) associations as well as an instrumental variable (IV) estimate consistent with their hypothesized causal framework and identification strategy. ${ }^{5}$

\subsection{Early Investigations of the Allocation of Women's Time and their Fertility}

Women's labor supply in the United States differs depending on their marital status, number of children under age 18, and in particular the number of their pre-school-aged children (e.g. Mincer, 1962). Early investigations tried to infer from these empirical regularities in the United States how changes in marital status and fertility might have contributed to the increases in female market labor supply in the $20^{\text {th }}$ century. Goldin (1990), for example, treats marriage and number of children as exogenous factors in her US simulation of the gender wage gap, and concludes that the decline in fertility contributed to the increase in women's labor force participation, which reduced the pay gap between women and men. The mechanism is intuitively clear that with fewer children, the productive value of a mother's time at home for child care diminishes, encouraging her to work outside of the family in activities which can not be readily combined with her customary child care responsibilities (Heckman, 1974).

But fertility and female labor supply are both decisions over which women exercise some choice; it is plausible to imagine that variables unobserved by the researcher, such as parent preferences for children and working in the home covary positively, in which case the negative association observed between fertility and mother's market labor supply is likely to overstate the causal relationship. Rosenzweig and Wolpin (1980b) postulate that heterogeneity in women's preferences for childbearing and for work in the labor market are systematically related, and I would propose that they are generally inversely related. This proposed pattern of preference heterogeneity would lead to a larger negative correlation between fertility and female market labor supply than would be observed if fertility declined due to an exogenous decline in the price of birth control, for example.

${ }^{5}$ The Hausman specification test provides a basis for assessing the severity of the statistical bias due to neglecting the simultaneity or heterogeneity problem. If the statistical discrepancy between the OLS and IV estimates is empirically unimportant, the specification test is likely to not reject the null hypothesis that fertility is exogenous with respect to the relevant family outcome variable. In this case, the OLS estimate may be preferred, because it does not appear significantly biased and it is likely to be more precisely estimated than the IV estimate. 
The market wage of women may be initially assumed to be exogenous to family lifetime decisions, but in response to an exogenous decline in fertility, wage offers for women might be expected to first decrease as women have fewer children women and seek alternative work, but as they then invest more in market oriented vocational experiences which enhanced their market productivity, their rising market wages will reinforce the substitution of their time away from home production and further into the market. This possible scenario is not empirically documented in a convincing manner, although the long term study of Matlab, Bangladesh may provide some estimates of these effects of family planning on women's human capital accumulation, but they are evident only among the better educated.

Reallocating women's time from home work to market work does not necessarily entail any additional private gain or social benefit. It may occur because the woman's household is more impoverished due to her husband's bad health or death, or because the market wage rates available to the women increase. Push and pull factors may both be relevant to women's labor supply behavior, making the time allocation of women, and for that matter the time allocation of children, an interesting dependent variable, but not a unambiguous indicator of the welfare of the private individual, their family, or society.

\subsection{Coordination of Reproduction, Production, and Consumption}

The empirical strategy follows from the conceptual framework outlined in section 4 in which lifetime decisions of couples, including fertility, labor supply, human capital investments in children, and physical savings, are determined jointly and simultaneously over a lifetime. Research can then proceed to either estimate a reduced-form or a structural model of these family choices or coordinated behaviors.

A reduced-form equation can be approximated in which each family choice variable is expressed as a function of all observed environmentally fixed constraints on the family, thereby excluding from the list of explanatory variables those which are thought to involve any element of lifetime choice for the family. These reduced-form estimates may provide a basis for evaluating policy, if the policy is administered as a randomized social experiment, such that the differences in treatment are not correlated with unobserved determinants of family behavior. Even if the policies are exogenous to the family's preferences and constraints, the reduced form does not indicate the pathways by which the policy works to influence family outcomes. But this need not be a critical limitation for many reasons.

Reduced form estimates, because they are not dependent on a potentially controversial choice of an "exclusion restriction" can be estimated side-by-side for fertility and other observed family outcomes. Insight into the system of household behaviors may be gleaned from comparing this series of reduced form equations. Hypotheses can be proposed to account for how parents treat different outcomes, as substitutes for children, or as complements. Reduced form studies have examined data from India (Duraisamy and Malathy, 1981; Rosenzweig and Wolpin, 1982), Colombia (Rosenzweig and Schultz, 1982), Bangladesh (Hussein, 1989), Cote d'Ivoire 
and Ghana (Benefo and Schultz, 1996), for example. ${ }^{6}$ Some evaluations of family planning programs estimate the fertility effect of local expenditures or field staff time per woman of childbearing age, as in Taiwan and Thailand (Schultz 1973, 1992), while controlling for household characteristics which are assumed to be exogenous determinants of fertility demands. In other investigations, repeated cross sections are pooled and fixed effects are included for regions, and the effect of the family planning program is identified from variation in the intensity of treatments over time within program administrative regions (Gertler and Molyneaux, 1994; Schultz 1973, 1980). However, the local variation in family planning program treatment may not be independent of the local population's preferences or unobserved characteristics, because governments may systematically allocate program resources to where they believe the program services are most needed. Individuals will also tend to migrate, other things equal, to reside where local services appeal most strongly to their preferences (Rosenzweig and Wolpin, 1986). Thus, even with the inclusion of community fixed effects, the within community changes and trends in program activity may be correlated with changing unobserved parent preferences (via migration) or demand determinants ( such as changes in local factory employment opportunities for women). Miller (2005) extends this approach in his study of the Colombian family planning program, in which he allows for regional fixed effects and distinct regional trends, while evaluating the family planning program effects on fertility and women's subsequent labor supply and the schooling of local children.

Rosenzweig and Evenson (1977) estimate a system of reduced form equations across Indian 1961 Census districts to account for a relatively comprehensive set of family outcomes, including fertility, labor supply, and school enrollments for boys and girls. But to prescribe even the sign of the partial effects of exogenous constraints such as the wages of children on child schooling and child work decisions, the researchers had to assume additional structural assumptions such as which family outcomes were substitutes and complements for each other, and when price effects dominate income effects. Reduced-form estimations may thus be informative regarding the effect of exogenous policy variation, but not always be very helpful in testing restrictions implied by economic theory of household choice.

The alternative to estimating a reduced form is to assume fertility affects specific other family choices or outcomes, and then to estimate this structural equation which includes the

${ }^{6}$ A study of the Colombian 1973 Census sample began by estimating reduced form equations for children-ever-born and child mortality rates of women by age cohorts separately for rural and urban residents, and found across 900 municipalities that more local expenditures on family planning and more clinics per capita are associated negatively with fertility and child mortality, controlling for the woman's characteristics and the community climate and infrastructure (Rosenzweig and Schultz, 1982). Subsequent research reported to USAID exploited information on malaria prevalence to identify the cross effect of child mortality on fertility, by assuming that malaria affects only child mortality, whereas fertility is only affected by family planning expenditures. These conditional demand estimates of fertility on child mortality were small and never statistically significant, whereas the child mortality effects on fertility were large and significant in all six urban age groups of women, but not among rural women for whom fertility is still very high at older ages. 
parameter of interest. This estimate of the "cross effect" of fertility on say child quality, then requires an identification restriction. The conventional simultaneous equations approach to estimating such a structural relationship is to propose an "exclusion restriction" which typically specifies a variable that affects fertility but does not affect the other family outcome, except through its mediated impact on fertility.

\subsection{Structural Estimates of the “Cross Effects” of Fertility on Family Outcomes}

To assess fertility as an independent factor in development, and a lever on which policy interventions may operate, estimates are needed of the "cross effects" of policy-induced changes in fertility, which thereby modify other aspects of family welfare or other social outcomes that society values positively or negatively. Estimating the economic cross effects of policy-induced declines in fertility on women's productivity and on child human capital formation are therefore central objectives of this paper. But the empirical literature that recognizes the joint and simultaneous determination of fertility and family lifetime outcomes is sparse, probably because there is little consensus on what variables are valid exclusion restrictions for the purposes of estimating how fertility causes these changes in family outcomes. In addition, it would seem likely that the estimated cross effects of fertility will depend on the choice of identifying instrument for a particular policy mechanism, because of the heterogeneity in the population's response to any specific treatment approximated by different instruments. In other words, the effect estimated from variation in a policy variable represents a specific "local average treatment effect "(LATE) of modifying the fertility of certain groups in the population (Imbens and Angrist, 1994; Heckman, 1997; Moffitt, 2005). With this interpretation of what instrumental variable (IV) estimates are measuring, it is reasonable to select the instrument to predict fertility so as to replicate the effect of policies governments or non-profit organizations view as feasible and costeffective. Then the LATE estimates will represent the likely consequences of this policy treatment.

There are few long-term studies to document how randomly assigned treatments of a population to family planning or reproductive health programs have impacted fertility and other family outcomes. I return later to the case in Matlab Bangladesh. Lacking situations where instruments arguably represent a random treatment, most empirical research on the causal effects of fertility has gravitated toward the use of two instruments which capture variation in fertility which is arguably exogenous to parent demand for births: (1) twins or multiple births by parity, and (2) the sex outcomes of early births. These instruments explain only a small share of the variation in fertility, but this explained share is arguably independent of the demand for children and thus uncorrelated with preferences and constraints. Twins are more readily interpreted across cultures as an instrument, because they represent a "treatment" of a woman to an unanticipated "shock" or increase in her biological supply of births, irregardless of the sex of those children. But twins have the disadvantage of occurring infrequently, in the sense that they normally affect less than one percent of pregnancies, and therefore a large sample is required to obtain precise estimates from this instrument of the cross effect of fertility and they depend on the parity of the twin and the definition of the counterfactual or control group. ${ }^{7}$

${ }^{7}$ Rosenzweig and Wolpin $(1980 \mathrm{~b} ; 2000)$ emphasize that parents have a goal in terms of the number and timing of births, and the effect of a birth on the mother's labor supply will differ 


\subsection{Twins as an Exogenous Instrument for Fertility and Labor Supply}

Rosenzweig and Wolpin (1980b) analyzed twins as a rationing device which allocates number of births per woman more or less randomly, as well as modifies the timing of births. They propose a two-period model of fertility and mother's labor supply to illustrate that the cross effect of a "twin on first birth" on the mother's labor supply would be larger in the first period than in a second period. They also postulate preference heterogeneity on the part of couples, by which they mean those with stronger than average preferences for numbers of children also tend to have different preferences for women working in the market labor force. I would propose that this preference heterogeneity would bias the directly observed cross effect (estimated by ordinary least squares-OLS) of fertility on labor supply to be a larger (absolute value) negative effect than if this cross effect were estimated on the basis of an exogenous shock of a "twin on first birth'. They also argue the need to control for age at first birth in their model to deal with the timing of births within the biologically fixed reproductive span of the couple. Conditioning their labor supply estimates on the age at first birth, which they recognize is an endogenous decision variable, complicates the interpretation of their estimates as long run equilibrium responses (Rosenzweig and Wolpin, 2000). They analyze the 1965 and 1973 U.S. National Fertility Surveys from which they obtain samples of about 4000 women who had a first birth before age 25 or after age 24. Their estimates based on 87 twins are imprecise but generally consistent with their framework.

This approach to using twins as an instrument for exogenous variation in fertility has been employed in a growing number of studies, which although they were initially mostly in highincome countries, have helped to clarify the conceptual framework as it is extended to low income countries. Bronars and Grogger (1994) rely on the 1970 and 1980 U.S. Census publicuse-microdata-samples to obtain a much larger number of twins. Angrist and Evans (1998) use "twins-on-second-birth" or "sex outcome of the first two births", or both, to estimate by instrumental variables how fertility exerts a "cross effect" on several dimensions of the mother's labor supply. Both studies find women with twins have higher fertility and diminished labor supply. Of importance for this paper, the IV estimate based on twins on second birth as an instrument are about half as large in absolute value as the OLS direct estimates, and Hausmantype specification test suggest fertility can be rejected as exogenous in the labor supply equation

depending on when the labor supply is measured, e.g. the year after the birth or twenty years thereafter. A "twin on first birth" may provide parents with the time to adopt contraception and avoid having more births than they want over their lifetime, if they wanted two or more. But the parents still have to accommodate the unwanted timing of their first two births. A contraceptive failure leading to an unwanted or mistimed birth could have different implications, if it occurred before marriage or after, or if it occurred on the first or after the last intended birth. Models dedicated to explaining the timing of births have not been widely replicated, perhaps because the theory of demand for timing of births has not derived novel and testable implications which are distinct from those implied by the static lifetime model (Willis, 1973; Becker, 1981; Wolpin, 1984, 1997; Heckman and Walker, 1991). Twins are also different from singleton births; on average they are lighter and less healthy, and twins may require different reallocations of family lifetime resources than mistimed singleton births (Behrman and Rosenzweig, 2004). 
of the mother. The smaller IV estimate is thus preferred as an unbiased measure of the crosseffect of fertility on the mother's market labor supply. Hypothesis (3) in section 4 was that the nonmarket time or leisure of mothers appears to be a complement with numbers of children, and this prediction is consistent with these studies, in which case the neglected compensating income effect associated with the extra birth would presumably decrease the demand for a mother's leisure or nonmarket time, and thus understate any complementary cross effect of fertility on demand for nonmarket time.

\subsection{Twins as an Instrument for Fertility and the Demand for Child Human Capital}

Another within-family consequence of fertility could arise if the number of siblings affects the consumption, productivity, and welfare of a child. In other words, it has been hypothesized that parents who have more children commit less of their time and resources to each of their children (e.g. Becker, 1960; Becker and Lewis, 1974; Becker and Tomes, 1976; Zajonc, 1976 ; Blake, 1989). ${ }^{8}$ This inverse relationship between what is called the "quantity of children" and the "quality of children" suggests that parents who are subsidized to have fewer children may also invest more, on average, in the human capital of their children, and thereby improve the health, education, migration and lifetime consumption opportunities of each of their children on average. This view of the tradeoff for parents between having more offspring and allocating more resources to each child, given their resources, is also a central idea in sociobiology and psychology (Zajonc, 1968; Dawkins, 1976; Becker, 1981). Because society often intervenes to subsidize or organize social services to improve childhood nutrition, public health, and schooling, the magnitude of this causal quantity-quality tradeoff could be a motivation for society to assist couples to avoid unwanted births, or to subsidize birth $\operatorname{control}^{9}$. These empirical regularities would appear to be consistent with hypothesis (1) in section 4 that exogenous changes in the number of births affect inversely the per child levels of human capital, holding constant the family's income, or that child quantity and quality are substitutes. But it should be obvious that these empirical regularities do not test this hypothesis, because they are not based on exogenous variation in fertility that is independent of heterogeneous parent preferences or unobserved economic constraints, and these regularities do not compensate for the gain in income associated

${ }^{8}$ Becker (1960: p. 217) conjectured: "Because (child) quality seems like a relatively close substitute for quantity, families with excess children would spend less on each child than other families with equal income and tastes. Accordingly, an increase in contraceptive knowledge would raise the quality of children as well as reduce their quantity."

${ }^{9}$ In those states which first legalized abortion in the United States, the frequency of crime two decades later appears to have diminished significantly. A study has explored many aspects of these data and argues that the increased access to abortion, as a means for avoiding unwanted children among the poor, led to a reduction in youth from disadvantaged backgrounds in those states, which was the cause for the decline in crime (Donohue and Levitt, 2001). One interpretation of their instrumental variable estimates of the determinants of crime is that policy which reduces unwanted childbearing (i.e. legal access to abortion) helps not only poor women and their children, but also relieves society of the external social costs of crime. Indicators of child welfare and living conditions are also shown to improve for children whose parent had access to legal abortion (Gruber, at al. 1999). 
with a policy intervention, such as a birth control subsidy, which could also explain why a population poicy contributes to child quality.

Cross tabulations of census, administrative, and survey data show that the number of siblings an individual has tends to be inversely related their schooling or their success in the labor market (Becker, 1960; Blake, 1989). But even this direct empirical correlation is not observed in all rural low-income populations where education levels are low. For example, Maralani (2004) documents in the Indonesian Family Life Survey collected in 1993 and 1997 that a woman's completed fertility and the schooling of her children are not inversely related in rural areas.

Among women residing in urban areas, the "modern" quantity-quality tradeoff is significantly different from zero only for the youngest women age 20-29. ${ }^{10}$ Montgomery et al (1995) analyze Living Standard Measurement Surveys from Cote d'Ivoire and Ghana collected in the late 1980's and find little evidence that schooling of children is lower for women who have higher fertility. But even when the conventional inverse empirical regularity between these family choice variables is present, it does not imply that an exogenous increase in fertility would necessarily depress the school attainment of a woman's children, or vice versa. To test the quantity-quality hypothesis, the researcher requires variation in quantity (e.g. completed fertility or number of siblings) which is caused by an exogenous variable -- one which is arguably uncorrelated with desired, demanded, or preferred fertility or otherwise affected by the lifetime wealth of families and relative prices.

Based on the Additional Rural Income Survey of 1969-71 from India, Rosenzweig and Wolpin (1980a) use the frequency of twins per completed pregnancy as an exogenous determinant of the woman's completed fertility. This approximately random instrument is then shown to be significantly associated with lower levels of completed schooling of the woman's other (non-twin) children, based on 25 twins in 1633 families. If one assumes that the rate of twining is independent of other determinants of schooling, income, etc., fertility is increased by about .8 births by a twin, and this exogenous shock to fertility induces the family to substitute away from schooling per child. In a rationed consumer demand framework where the allocation of twins is an exogenous shock to fertility, the negative cross-effect of fertility on schooling per child suggests that parents treat their number of children and the human capital per child as substitute, neglecting the negative income effect that would also reduce the demand for schooling.

The occurrence of twins on a specific parity has been used to instrument for the total number of children in a family (sibling number) in order to explain various measures of human capital of children born before the twin, or other life course events, such as the child's age at

10 I would conjecture that at the low levels of schooling attained by the children of older rural Indonesian women, schooling was not a major cost of childbearing, and wealthier rural parents sought more children and provided them with more schooling because their existing land allowed them to employ more complementary child labor, adding to their traditional incentives for more chidlren. In the urban sector where today the average child receives some secondary schooling, and children are a less important source of family income, the modern trade-off is clearly evident in the cross section. However, this does not mean that family planning programs have increased the schooling of children. But the hypothesis warrants more study. 
marriage in the case of daughters. The OLS estimates of the effect of child quantity on indicators of child quality tend to yield strong negative relationships, but the IV estimate identified by twins tends to be smaller in absolute value, and sometimes insignificant and even positive in sign in some cases (e.g. Angrist, et al. 2006, in Israel; Qian, 2006, in China). Does this imply that quantity and quality are not substitutes and that population policies which achieve a voluntary reduction in fertility would not induce an increase in child human capital?

Rosenzweig and Zhang (2006) consider the possibility that parents might allocate their resources in children to compensate (or reinforce) endowments differences among their children (Becker and Tomes, 1976). However, twins themselves may have below-average endowments, as clearly is the case for their birthweight. The question is then how parents compensate across their children for the below-average twins, and will this behavioral process affect the estimated "cross-effect" of twin induced fertility variation on child quality which will combine a negative wealth effect of the involuntary fertility shock and mistimed spacing of births, as well as the compensation effect among their children. In their framework Rosenzweig and Zhang (2006) show that if parents reinforce endowment differences among children, as they empirically observe in their sample of twins from Yunnan Province in China, the twin effect on twins's quality is a lower bound (more negative) estimate of the true average effect, whereas the twin effect on the quality of younger non-twin quality is an upper bound (more positive) effect of the average cross effect. They conclude, therefore, that the results from estimating twin effects on non-twins, as commonly reported in the literature, is an upper-bound estimate and hence positively biased toward rejecting substitution between quantity and quality which implies a negative cross effect. This does not however, modify the implications of the empirical regularity emphasized in this paper that using twins as an instrument for fertility generally reduces in absolute value the estimated fertility effect on child quality and on the mother's labor supply. ${ }^{11}$

\subsection{Fecundity approximated by the Residual from a Fertility Production Function}

Another way to distinguish exogenous variation in fertility is to recover a measure of biological heterogeneity or a couple's fecundity by assuming more structure for the reproductive process and predicting the choice of contraceptive practice during each reproductive cycle. In other words, contraceptive practice and the conception rate of a couple are used to infer the

11 One final example of twin-instrumented fertility variation investigates birth orderspecific effects of twins on schooling of earlier births in Norway, a high-income low fertility setting. Using data for all persons, Black, et al (2005a) rely on twins on a second or subsequent birth as an instrument to predict the completed schooling of a woman's children (currently age 25 or more) born before the arrival of the twins. The twin-induced variation in the mother's fertility is not a statistically significant determinant of the children's schooling, based on the IV estimate, with or without controls for birth order. The conventional OLS relationship, however, is strongly negative (Black, et al. 2005a: Table 6). Their evidence is consistent with heterogeneity in women's preferences for going to school and for reduced childbearing (or another unobservable variables such as ability) which contributes to the spurious inverse direct OLS relationship. Norwegian mothers may be able to compensate for the effect on the "quality" of earlier children of having a later twin because of the egalitarian welfare and schooling systems in Norway, which would not be present in a low income country. 
couple's latent reproductive endowment or biological fecundity. ${ }^{12}$ Based on the 1976 Malaysian Family Life Survey this measure of fecundity is estimated from reproductive calendars from 1971-76 (Rosenzweig and Schultz, 1987). This residual is a continuous variable approximating a couple's reproductive "endowment", given their predicted contraceptive behavior, and is roughly analogous to the effect of a twin. Controlling for her education, age, and husband's earnings, this fecundity variable is associated with more children ever born, use of more effective contraception $(n=816)$, lower birth weight for her children, and less schooling per child (Rosenzweig and Schultz, 1985,1987). All of these IV estimates of the effects of exogenous residual fertility on child quality outcomes are smaller in absolute value than if they are estimated as the direct partial association between actual fertility and the indicator of child quality. ${ }^{13}$

Fertility and child health outcomes are analyzed as joint choices in the Kenyan Welfare Monitoring Surveys of 1994 and $1997(n=4921$, 3206), in which the rate of twinning per completed pregnancy is employed as an instrument for children ever born among women over age 35 , controlling for age, region, etc. The negative partial correlation (OLS) between fertility and child health is significant, but this association becomes smaller and less statistically significant when the mother's fertility's effect on child health is estimated using the rate of twinning as the instrumental variable (Schultz and Mwabu, 2003). ${ }^{14}$

${ }^{12}$ Desired family size and accumulating knowledge by the couple of their reproductive endowment is expected to influence whether they use a contraceptive in each period, and the effectiveness of the method they choose. The technical effectiveness of various contraceptives to reduce fertility is first estimated in the form of a two-stage fertility production function, in which local prices and household characteristics affect the couple's demand for contraception. Then this estimated model and the actual contraceptive practice are used to recover the residual variation in a couple's latent rate of conception (Rosenzweig and Schultz, 1985). The couple's unexplained variation in fertility is then interpreted as a noisy measure of the couple's fecundity.

${ }^{13}$ The Demographic Health Surveys distinguish if a woman's births were mistimed or unwanted ever. Montgomery and Lloyd (1999) find the schooling of a woman's children is not uniformly associated with mistimed and unwanted births in the last five years in four lowincome countries. Rosenzweig and Schultz (1987) find that their residual estimate of fecundity of couples in Malaysia is significantly correlated with the couple's reporting their last birth unwanted or mistimed. The respondent's classification of a birth as mistimed or unwanted is, however, arguably subjective and endogenous itself, invalidating it as an exogenous instrument for latent fecundity, or even as a basis for checking the reasonableness of the fertility production function estimates.

${ }^{14}$ The health of children under age five is summarized by height-for-age and sex, and weight-for-height by age and sex, expressed as standardized $\mathrm{Z}$ scores, which is defined as the child's deviation from the median child of the same age and sex as observed in a well nourished (US) population, expressed in units of standard deviations for each age and sex group. The findings are robust to constructing the $\mathrm{Z}$ scores around Kenyan median anthropometric growth curves for children rather than those derived from US population figures. 
Kim and Aassve (2006) estimate the determinants of conception rates from the 1989 and 1992 from the Indonesian Family Life Survey $(n=4548)$ including endogenous choices of birth control by type, with community fixed effects, identified by the couples' education and Muslim religion. Persistent and transitory exogenous measures of individual fecundity are then defined from this estimated model, predicted inputs, and fertility, following Rosenzweig and Schultz (1987). The permanent component of fecundity for a couple accounts for a significantly lower level of mother's labor supply in 1993 estimated as a Tobit model. When this estimated impact of exogenous fecundity is rescaled to be in units of births, it is about one third of the magnitude as the coefficient obtained by alternatively including the couple's actual number of births from 1989 to 1992 in the log labor supply equation for women. Thus, the OLS estimate which treats fertility is exogenous is substantially larger in absolute value, or -.220 a birth on log weekly hours, than the IV derived estimate which -.069. Moreover, this anticipated female labor supply effect of fecundity is statistically significant and substantial only among rural residents in 1993. In addition, Kim and Aassve estimate the parallel specification of their model for the husband's labor supply as affected by permanent and transitory fecundity, and find that the husband's labor supply (ln weekly hours) increases by .024 in the rural areas due to a birth according to the IV estimate ,and by .062 according to the OLS estimate, and does not respond significantly in the urban areas. The implication is that women's and men's labor supply responses to fertility are offsetting to a degree, but these plausible family specialized labor supply effects are evident only in the rural economic setting of Indonesia.

Because multiple births occur naturally infrequently, twins may not be an ideal instrument for fertility unless large census samples are available and the reporting of twins is very accurate. On the other hand, estimating fertility production functions in order to "back out" an exogenous measure of fecundity requires extensive and complete information on birth control behavior and its environmental determinants. Other biological markers for fecundity may also be directly observed in a household survey, although they may not be measured without systematic error. An alternative instrument for fertility (or conceptually fecundity) may be a woman's experience of miscarriage. Xia Li (2005) analyzes whether a woman on her first pregnancy experiences a miscarriage (and on subsequent pregnancies for later birth orders). Miscarriages are reported in roughly 11 percent of first births in the 1988, 1995, and 2002 in the U.S. National Survey of Family Growth $(n=12,000) .{ }^{15}$ Using a miscarriage on first pregnancy to identify exogenous variation in fertility, she finds the probability of miscarriage is negatively and significantly related to children ever born, suggesting the instrument proxies subfecundity or a discouragement effect of miscarriage on the demand for childbearing. ${ }^{16}$ The associated IV estimate of the cross-effect of

${ }^{15}$ Although miscarriages occur much more frequently than twins, the overall explanatory power of miscarriages as an IV for fertility is not much higher than twins in these US surveys.

${ }^{16}$ If all women are not equally aware of an early miscarriage, or some fail to report this event, this instrument could be measured with error, and if reporting error is related to the demand for children, it could undermine its validity for an exogenous instrument for fertility. The main limitation of miscarriage as an instrument is that its reporting could be subject to systematic errors of measurement and recall, especially if it includes some induced abortion. 
fertility on a mother's labor force participation and hours worked is negative, and about one half the absolute magnitude of the directly estimated (OLS or Probit) associations.

\subsection{Sex Composition of Births as an Instrument for Fertility and Labor Supply in High- Income Countries}

A second instrument proposed to identify independent variation in U.S. fertility is the sex of the first two births, where the sex composition is hypothesized to be independent of preferences for numbers of children or of unobserved variables affecting female labor supply (Angrist and Evans,1998). In the case of sex composition, the power of the instrument(s) to predict fertility depends on parents having a distinct reproductive response to different combinations of boys and girls, and the direction of the OLS bias will depend on how this gender preference is related to preferences motivating women's labor supply or demand for child quality. This is more complex than in the case of twins which is a plausible surrogate for fertility without regard to gender preference. Angrist and Evan (1998) reports that a US couple is about 15 percent more likely to continue to have a third birth (.46 versus .40 in the 1980 Census) if their first two births are either both boys or both girls. In other words, parents prefer to have at least one boy and one girl. When having a third birth is predicted on the basis of the sex outcome of the first two births, the IV estimate of fertility's effect reducing the mother's labor supply is again much smaller in absolute magnitude than the OLS estimate. ${ }^{17}$

Jacobsen et al (1999) also examine the 1970 and 1980 U.S. Censuses and use as their instrument for fertility "the sex of the first two births" and obtain negative IV estimates of the cross effect on labor supply which are significantly smaller in absolute value than the OLS estimates. Sampling from the same birth cohort of women represented in the 1970 Census and among those ten years older in the 1980 Census, they show that the labor supply IV effects of fertility on mother's labor supply diminished as the cohort ages, consistent with the birth timing framework as proposed by Rosenzweig and Wolpin for the study of the behavioral effects of twins (1980b).

The sex of the first two births and whether the second birth is a twin are analyzed by Iacovou (2001) as instruments for predicting the probability of women continuing to have a third birth in the United Kingdom, and the resulting effect of this IV variation in fertility on the mother's labor supply. Estimates are for women with two or more births in the National Child Development Study which includes a cohort born in a week in 1958 and followed through 1991

\footnotetext{
${ }^{17}$ Angrist and Evans (1998) also report evidence across age groups suggesting that the labor supply effect of the twin on second birth or same sex outcomes are larger (negatively) for younger women for whom the marginal birth may be a more recent event, consistent with the Rosenzweig-Wolpin (1980b) timing model. The OLS estimates of fertility's effect on the mothers labor supply in 1980 are consistently larger in absolute value than the IV estimates across different dimensions of her work and its value: (1) working for pay ( OLS from -.18 to IV -.12), (2) for hours per week (-6.7 to -4.6$)$, (3) weeks per year ( -9.0 to -5.7$)$, and (4) in terms of total annual labor income of the mother $(-\$ 3768$. to -1961 .). Their estimates from the 1990 Census are similar. Clearly, this estimate only pertains to the self-selected sample of the population who have two or more children.
} 
$(\mathrm{n}=3188)$, and a British Household Panel Study from 1991-1992 ( $\mathrm{n}=1374)$. According to the direct partial association (OLS), a third birth is significantly negatively associated with the woman participating in the labor force and her hours of work. But when the effect of the third birth on labor supply is estimated by IV methods, the cross effect on labor supply is no longer statistically different from zero in either sample, and indeed its sign becomes positive. The inverse OLS association between fertility and female labor supply in the UK is apparently not the same as these IV estimates of the impact of an exogenous birth. Heterogeneity in preferences for children and women's work, or other unobservables correlated with fertility and female labor supply in opposite directions, could explain these findings from the UK.

\subsection{Sex Composition of Births as an Instrument for Fertility in Labor Supply in Low- Income Countries}

Parent preferences for the sex of their offspring may differ widely across cultures, and could also change with economic development. There are, however, at this time relatively few studies in low-income countries from which to generalize. In some settings there is a strong preference for male offspring, as distinct from the preference for having a child of both sexes as described by Angrist and Evans and observed in the US and UK. There would appear to be substantial effects of sex composition of children on the lifetime wealth of a family in some areas of Asia, perhaps because parents must provide a daughter with a dowry, whereas they can expect to benefit from a dowry paid to their sons, when they marry ( Rose, 2000). Thus, the sex composition of births in such an Asian context can involve not only a potential effect on fertility, but also on family wealth and relative prices which affect other family members. Sex composition of births as an instrument for fertility is therefore invalid, because it will not approximate the "cross effect" of a supply shift of fertility on family outcomes, as it will be inseparable from potentially large changes in family wealth, which may also be a complex function of class or caste in which customs surrounding marriage and dowries differ.

Chun and Oh (2002) use the sex of the first child in Korea as an instrument in the first stage regression for fertility, before estimating in the second stage for the women's labor force participation as a function of fertility. They analyze the 1996 wave of the Korean National Survey of Family Income and Expenditures $(n=3997)$. Having a male on first birth is associated with a woman having . 15 fewer children at the time of the survey; Korean parents appear to be more likely to stop bearing children after having a male birth than a female birth, and the effect of a second male birth is to reduce further the likelihood of continuing to a third birth. Estimates of fertility's effect on female labor force participation based on this IV strategy implies participation is -.28 for each child, whereas the OLS estimate is also statistically significant but smaller in absolute magnitude , -.06 . This is an unusual case in this paper where the IV estimate of the cross effect of fertility on a family outcome is larger in absolute magnitude than the OLS estimate of the same parameter. This pattern is consistent with there being an income effect associated with having a male offspring that encourages a mother to engage in more home production or leisure, or due to the hypothesized (3) cross-substitution effect. This empirical regularity suggests that the local average treatment effect (LATE) of a male on first birth is to decrease the woman's labor supply by a greater amount than is the case for all fertility which includes girls (Imbens and Angrist, 1994). Apparently in Korea, women whose fertility is most affected by their preference to have a male child are also as a consequence less likely than the average to work in the labor force, perhaps because they regard themselves as wealthier with a male offspring to rear. And 
because the boy is valued more highly, it might be expected that the mother would allocate more of her time to the care of the son than to a daughter, even though gender differences in schooling and health across siblings may diminish with increasing household income (Schultz, 2001).

Heterogeneity in traditional values toward the sex of offspring could explain why Korean parents who have a relatively stronger preference for their offspring to be male, tend to also have a relatively stronger preference for mothers to not work outside of the home, or at least to dedicate more of her time to the task of rearing the son.

It should be noted that technological developments may also undermine the validity of these two instruments for measuring exogenous variation in fertility. Techniques to test for the sex of the fetus early in a pregnancy (e.g. by means of ultrasound, amniocentesis, or chorionic villus sampling) allow parents who have a sufficiently strong preference for the gender of their child to abort a fetus of the unwanted sex. If this occurs, the sex composition of children may become correlated with the couples' preferences for women to work (and other family choice outcomes), and sex of the child cease to be a valid instrument for estimating the cross-effect of fertility. The increasing number of male to female births at each successively higher parity in countries such as Korea, China, and portions of India reflects probably a strong preference for male offspring. ${ }^{18}$

Since about 1980 in high-income countries, twins are also becoming an unsatisfactory instrument for exogenous fertility variation, because drugs administered to assist parents to conceive also increase the probability of having a multiple births. Because parents with multiple births are increasingly likely to have used fertility enhancing drugs, twinning will be correlated with subfecundity, on the one hand, and also with relatively strong preferences on the part of parents for additional children. It can no longer be confidently assumed that twins or multiple births are uncorrelated with the preferences of parents for childbearing or for women working in the market labor force, or for that matter unrelated to income, since the infertility treatments tend to be privately costly in most countries.

\subsection{Sex Composition of Births as an Instrument for Fertility and Child Human Capital}

Other studies estimating the effect of exogenous variation in fertility on child quality have used the sex composition of births. It should be reemphasized that these instruments have explanatory power to predict fertility among parents who have a strong preference between having boys and girls, and are selected in a culture-specific manner. In some settings they will also capture substantial income and other price effects that could change long run family outcome

18 By 1989 the ratio of male to female births in Korea increased from a normal value of 1.06 for first births, to 2.17 for fourth-order births (Schultz, 1997, Table 4). Models of fertility estimated from Chinese data for women with at least one birth also reveal the strength of traditional male preference, in which the share of male births reduces the likelihood a Chinese woman will have an additional birth at all estimated parities (Schultz and Zeng, 1995). However, it has been observed that the sex ratio of births may be affected by the prevalence of Hepatitus B Virus, which may offer a supplemental biological mechanism for exogenously modifying the regional pattern of sex ratios at birth by region as in East Asia where the prevalence of hepatitus is substantial and regionally varies (Oster, 2005). 
variables and therefore do not necessarily predict how population policies would affect behavior (Rose, 2000; Deolalikar and Rose, 1989).

Lee (2004) analyzes the determinants of fertility and child educational investments in Korea. He examines the Korean Household Panel Study from 1993 to 1998 ( $n=5180)$, and finds that if a woman's first child is a girl, the woman is more likely to have a second birth, and the time to the second birth is also shorter, according to a fitted hazard model. The same is true for continuing to a third birth, if the first and/or second births is a girl. Relying on whether the first birth is a girl as an instrument for completed fertility, Lee finds the direct (OLS) estimate of the elasticity of educational investment per child with respect to fertility is -0.5 , whereas the instrumental variable estimate of this elasticity is -0.3 . The observed relationship between women's fertility and the education of their children is thus weakened when identified form variation in fertility induced by the sex composition of a couple's births.

Jensen (2005) hypothesizes that in India son preference is combined with a rule to stop bearing children only if the woman has a sufficient number of living sons. This he argues would lead girls to have more siblings than boys, on average, and thus receive less education in a larger family. In a 2001 Survey of Aging in Rural areas of five Indian states ( $n=2693$ households) Jensen reports that girls have .47 more siblings if the first child in their family is a girl and .76 more siblings if the first two births are girls (Table 5). Dividing his sample into those couples who indicate a son preference and a desire to educate sons more than daughters (51\%), the OLS estimated effect of an additional sibling is -1.2 years of schooling, whereas the estimated effect of siblings instrumented by the sex of the first two births is -.69. The quantity-quality tradeoff is still present, but diminished by about half when it is based on the response of couples to the sex outcomes of their first two birth.

The role of sex of offspring as an instrument for fertility or other family behaviors depends on the researcher to interpret cultural and economic repercussions of the sex composition, not just its impact of number of children born (Deolalikar and Rose, 1998; Rose, 2000). The sex composition of children can represent a random treatment, but its outcome on fertility is likely to depend on marriage customs and gender inequality in a specific society, as well as the couple's individual preferences for a wide variety of family lifetime outcomes. It is therefore not a valid instrument for fertility as an objective of population policy, in order to estimate the cross effects of fertility on long run family outcomes, which is a central motivation of this paper.

China after introducing the one-child quota policy in 1979, relaxed this policy after about 1984 in some regions and permitted rural couples with a girl as their first born to have a second child. Qian (2004) analyzes a sample of 28,771 households from the 1990 Census, drawn from 21 rural counties in four provinces for which she relies on the 1989 China Health Nutrition Survey to document the local timing of this relaxation in the birth quota policy. First-born girls born in 1976-81, who are resident in counties which relaxed their one-child rule, are shown to have 0.25 more siblings on average than first-born girls born in the earlier period of 1973-76, whose parents would have been more likely to be constrained by the one-child policy. Qian concludes from twostage least squares estimates of school enrollment conditioned on the local policy-induced change in number of siblings, that a one sibling increase due to the local government's relaxed policy is associated with an 18 percent increase in first-born girl's probability of being enrolled in school 
according to the 1990 Census. The census data, however, does not report education on children who have left the home, and migration which is increasing in this period could introduce a serious selection bias. The ordinary least squares estimate of the partial association of sibling number on girl's enrollment is significantly negative, as typically observed in the descriptive literature on child quality(schooling)-quantity(sibling number). If this policy-induced change in number of siblings is uncorrelated with unobserved factors determining differences in the parent's demand for male and female children's schooling, Qian's IV estimated cross-effect of increases in siblings on the schooling increases the schooling of the first born girls, but not of boys. Thus, increasing the quantity of children from the first to second birth order does not appear to elicit the anticipated negative substitution response in her sample. She regards this as evidence that the quantity-quality relationships is non-monotonic. ${ }^{19}$

One alternative interpretation for Qian's findings is that the relaxation of the one-child policy represents a large lifetime gain in wealth or welfare for families with a first-born girl. In many studies family income effects on the enrollment of girls tend to be larger than the income effects on the enrollment of boys (Schultz, 1995). If these income effects favoring girls schooling dominate any possible negative cross-substitution effect from quantity to quality, the policy relaxation could favor increased fertility and girls schooling. However, Quin does not find evidence for a positive income effect on fertility in her data. ${ }^{20}$

\subsection{Estimates of Population Program Effects on Fertility and Other Family Outcomes}

If the private cost of birth control is reduced by a population program, fertility is expected to decline. ${ }^{21}$ Table 1 proposed other family outcomes which might be affected during a family's lifetime by a program-induced decline in fertility. As stressed in this paper, many of these potentially important mechanisms have not been empirically studied, but could be analyzed by studying social experiments, matching studies, or well-designed instrumental variables to identify the effect of exogenous variation in fertility on these lifetime developments.

${ }^{19}$ The author's assumption that a four year interval between births was uniformly enforced in all counties of China does not seem realistic. One might also expect the local relaxation of the one-child policy would have been affected by the local demands of parents for additional births and not imposed for some exogenous reason. Although in one set of estimates controls are included for mother's schooling and household income, father's income is not included, and household income is not derived from a series of questions on expenditures or income sources, which are generally believed to produce a more reliable value for household income.

${ }^{20}$ As already noted, Rosenzweig and Zhang (2006) offer another explanation for her estimates of the cross substitution effect being biased in a positive direction.

21 A reduction in the price of birth control would raise the cost of children but also add slightly to income. The implicit assumption is that the price effect of population programs dominate the income effect, where children are presumed to be"normal" economic good exhibiting a positive income elasticity when relative prices are unchanged. 
Many forms of social welfare policy, including family planning and reproductive health programs, could be viewed as a possible program instruments affecting fertility, and variation in access to these programs could be candidates for exogenous program treatments, as outlined in Table 2. The random occurrence of twins and the reduction in the private cost of birth control due to a family planning program could influence fertility in opposite directions, but otherwise can be thought of as having an analogous exogenous effects on fertility, neglecting for the moment any consequences for income and biology on child quality. Heterogeneity in the individual's response to the policy treatment may also be important and can complicate simple differences in before-andafter evaluations which often assume for simplicity homogeneity in the response of the treated. ${ }^{22}$

The welfare consequences for different individuals of a supply shock to fecundity or a randomized exposure to a family planning programs will differ according to a couple's reproductive goals, their current number of surviving children, age, and fecundity. The private cost of a twin on first birth will be smaller for a couple who wants many children, than for a couple who wants only one birth. The private benefit of a policy-induced decline in the price of birth control is correspondingly smaller for the couple who wants many more children, than for the couple who wants no more children, other things being equal. The policy treatment provided by the independent family planning program and the twin on first birth yield instrumental variable (IV) estimates which identify a local average treatment effect (LATE). Adding to the model explanatory variables defined as the interaction of the program treatment intensity and the exogenous characteristics of individuals treated can help to assess whether heterogeneity in response to the program is substantively important, and how it is distributed across groups in the population (Schultz, 1992).

A key issue for social policy is whether a subsidy for family planning will not only reduce fertility, but also improve child quality and family welfare? Studies evaluating the success of family planning programs often stop with an evaluation of how contraceptive knowledge, attitudes and practices change following a program intervention. Even when the intervention treatment is designed as a randomized experiment across local residential areas, the common focus on short run adoption of modern means of birth control tends to overlook the longer run consequences (Cf. Taichung City Experiment in 1963, Taiwan, documented by Freedman and Takashita, 1969). Program evaluations should assess how completed fertility is impacted by the program, as well as the timing of births. Traditional means of birth control, such as prolonged breast-feeding, postpartum delay of intercourse, and even induced abortion, may diminish in the aftermath of a modern family planning program, implying that the uptake of modern contraceptives in the program will overstate the program's impact on fertility, as well as possibly overlook other welfare gains (Schultz, 1992). Even changes in fertility in the first few years after a program starts tend to overstate the longer run consequences on lifetime fertility, because initially the program achieves a better timing of births which may increase intervals between births and thereby cause a transitory dip in period-specific birth rates that will be less pronounced in final number of children-ever-born across a series of birth cohorts.

${ }^{22}$ See chapter in this volume by Duflo, Glennerster and Kremer. 
What can one learn from study of a family planning program's regional expansion about its long run consequences on family welfare outcomes? Miller (2004) estimates the relationship in Colombia between the timing of a woman's local exposure to the family planning program in the 1970s and her fertility in 1993. He then estimates the relationship between this exposure to the family planning program and a variety of indicators of her welfare and that of local matches for her children. Miller interprets these associations as unbiased reduced-form estimates of the consequences of the family planning program. This reduced form approach has the attraction that it captures the effects of family planning that may influence a variety of family outcomes, some of which may operate through fertility decline, while other program effects may empower women and foster changes in community social organizations, etc. Earlier exposure to family planning is shown to be positively related to the woman's years of education, work in the formal sector, and negatively associated with current cohabitation in 1993, but is surprisingly insignificantly related to the survival of her children. The household data cannot match the individual woman to her own children, and moreover those children who are enumerated in the mother's household can also be an unrepresentative sample of children, because the age of leaving home tends to be related to the child's schooling and the household's poverty. Miller reports evidence that "statistical mothers" with longer community exposure to family planning programs are associated with children who are more likely to be attending school, have completed more years of education, are less likely to work in the formal sector, and are less likely to have already had a child of their own by the time of the census. In sum, the study concludes that exposure of a woman to family planning from age 15 to 44 is associated with a reduction in cumulative fertility of 10-12 percent in urban areas, improvements in her educational attainment of 0.3 years, and an increase in her formal employment, an inter-generational increase in her children's schooling of 0.1 years, and a delay in a child's first birth (Tables 5, 9, 10). Similar patterns have also been estimated based on the earlier 1973 Census of Colombia where the focus is only on fertility and child mortality ( Rosenzweig and Schultz, 1982).

A limitation of Miller's study is that the Colombian family planning program started in the late 1960s in the major metropolitan areas, and then expanded in the 1970s and 1980s to serve smaller towns and eventually to reach rural municipalities. Those communities first served by the family planning program are thus unrepresentative of the Colombian population. Women in the metropolitan areas who were first exposed to the family planning program may already have had stronger demands for birth control than the average woman of that age within all urban or rural areas. The variable representing exposure to family planning for women of different cohorts within a region may therefore also capture the effect of unobserved changing characteristics of these neighborhoods which influenced fertility, etc. If these characteristics are not adequately controlled for by including, as Miller (2004) does, dummies for municipality and linear municipality trends, the estimates of the family planning program effect are potentially biased.

Miller tests his identifying assumption of exogenous program placement by comparing changes in fertility between women of different ages in the five years before a family planning program started in a region, and finds no pre-program relation to fertility or to the other welfare indicators (Table 7). The analysis also considers separately women in urban and rural areas, but may nonetheless need to deal with sample selection bias due to intersectoral migration. Excluding migrants and rural residents from one specification of the model begins to address this problem. Interregional migration is frequent in Colombia, especially from rural to urban areas, and already 
by 1973 migration is strongly related to women's fertility, child mortality, and children's education, conditional on the woman age, education, and region of birthplace (Rosenzweig and Wolpin, 1986; Schultz, 1988). Nonetheless, Miller's (2004) study illustrates how historical data can be used to evaluate the longer term welfare consequences of family planning. This general methodology might be used to evaluate family planning and reproductive health programs in other countries where they were introduced in a staggered regional fashion, even when the program's implementation does not follow an experimental design. But the burden of proof is upon the researcher to show that the program expansion did not follow other socioeconomic features of the population that are likely to influence economic and demographic behavior (Cf. Colombia by Rosenzweig and Schultz, 1982; Indonesia by Gertler and Molyneaux, 1994; and Taiwan and Thailand, Schultz, 1973, 1980, 1992).

\subsection{A Family Planning-Health Services Project in Matlab, Bangladesh: 1977 - 1996}

Social experiments randomly designed to document the efficacy of family planning programs to reduce lifetime fertility and to improve the long-run welfare of women and their families are rare. One widely cited example occurred in a relatively remote rural district of Matlab, Bangladesh where the population has been followed since 1966 with a Demographic Surveillance System (DSS). In this relatively homogeneous poor tidal delta region, an outreach family planning and health services project (FPMCH) was introduced in October of 1977 and maintained for two decades. The program trained local female field workers to visit all reproductive-aged married women approximately every two weeks. The field workers provided not only information regarding birth control methods, they also reduced the private time and perhaps psychic costs of obtaining birth control from government community clinics by offering in the woman's household a range of methods and instructions on their use, including the more popular injectables. In 70 of the 149 villages of the surveillance system this family planning program was initiated (Fauveau, 1994: Chap. 6). Nineteen years later in 1996 a comprehensive Matlab Health and Socioeconomic Survey (MHSS) interviewed 4363 households in 70 treatment and 71 control villages (Rahman et al. ,1999).

Sinha (2005) estimates from the MHSS the relationship between residing in a treatment village and women's fertility and indicators of child welfare. Reduced-form equations evaluate the effect of the family planning outreach intervention on fertility. Residential exposure to this experimental program $(n=4124)$ is significantly associated with women reporting 14 percent fewer children ever born in the 1996 MHSS. Phillips et al (1982) found after two years (1978-79) of program's operation, it was associated with a 25 percent reduction in the general fertility rate. As observed earlier, a program's estimated effect on period fertility may be larger in the short run, than on cumulative fertility in the long run, if during the initial transition to use the new technologies, contraception is used extensively to increase inter-birth intervals (Phillips, et al. 1988; Koenig, et al. 1992). ${ }^{23}$

${ }^{23}$ In Taiwan, analyzing the partial association of family planning program activity per woman across 361 districts, the apparent effect of the program on age-specific birth rates was larger in the first few years of the program than after five years, when the program's effect on fertility could no longer be precisely estimated from the cross sectional variation. Including regional fixed effects and estimating first differences did not change the results appreciably. The 
However, Sinha (2005) did not find greater school enrollment among boys or girls in the treatment villages compared with the children in the control communities, holding constant for the child's age, the parents religion, mother's age and education, and father's education, farmland, and distance to district headquarters (Cf. Table 7, $\mathrm{n}=1335,1165$ ). Residence in the villages exposed to the program is a significant instrument for predicting the woman's fertility, but the second stage IV estimate of the child's mother's fertility cross-effect on the school enrollment among either girls or boys separately (or together) is insignificant and small in magnitude (Table 9). Her findings do not support Becker's $(1960,1981)$ hypothesis that parents substitute quality (schooling) for quantity, when the price of birth control is reduced. ${ }^{24}$

Sinha also analyzes whether the program-induced decline in fertility contributed to a reduction in child labor, and finds no effect for girls and a statistically significant small effect of the family planning program treatment increasing the market labor supply by boys (Table 7). Thus, this program evaluation study of a long-term experimentally designed family planning and health project concludes that the program achieved a major decline in fertility. But the anticipated increase in children's school enrollment or decrease in child labor was not evident. In other words, the cross-effects of the fertility decline on child quality which may be viewed as an beneficial consequence justifying subsidies for family planning and child and maternal health programs in low income rural populations are absent. ${ }^{25}$

reductions in births related to an increased application of program staff per woman of reproductive age implies nonlinear effects, with diminishing returns to scale of effort (Schultz, 1973). A similar pattern of diminishing returns to scale is observed in Thailand's public family planning program as of 1970 (Schultz, 1992).

${ }^{24}$ Foster and Roy (1997) analyzed a 1990 Survey of the Matlab region and estimate the program's impact on fertility and its cross-effect on child schooling by the sex composition of the mother's children. Simulation of their estimated model suggests the program reduced fertility by 31 percent. Children born to women who first received program services at a young age are estimated to obtain 32 percent more schooling than similar children whose mothers did not receive program services at all (p.20).

25 Two limitations of analyses of the 1996 MHSS are that the comparability of the treatment and control villages before the program started had not extensively analyzed in the literature and migration into and out of the villages could be affected by the program, potentially biasing the inferences based on the sample of persons who remained in Matlab in 1996. Joshi and Schultz (2007) link the censuses of 1974, 1978, and 1982 to the treatment and control villages and find no significant differences in child-woman ratios (proxy for surviving fertility) in 1974 before the program started, and by 1982 this measure of fertility is 18 percent lower in the treatment than in the control villages, a differential which continued to be 16 percent lower in 1996. The potential bias due to migration from and into the Matlab demographic registration area was also estimated from the 1996 survey and was never statistically significant. This form of potential attrition bias in panel surveys warrants more study (Fitzgerald, et al. 1998). 
The Family Planning and Child Maternal Health program in Matlab offers an unusual opportunity to evaluate the long-term effects of an experimentally designed population program on both fertility and other life cycle consequences for women and their families. Joshi and Schultz (2007) explore these questions with several sources of data over time. A primary issue is whether the 71 treated and 70 comparison villages in the Matlab are comparable in terms of fertility and other economic development conditions before the program was started in 1977. With the 141 villages as observations, the first Census of the area in 1974 indicates no significant differences between the treatment and comparison villages in surviving fertility, approximated by the ratio of children age 0-4 to women age 15-49. By 1982 a Census shows surviving fertility in the treatment areas is significantly lower than in comparison villages by 18 percent, and this relative gap in surviving fertility remains 16 percent lower in the 1996 survey. ${ }^{26}$ Using a double difference methodology that controls for initial village levels of surviving fertility, the authors find the program appears to exert a large and persistent effect on surviving fertility. Although the 1974 Census does not include much socioeconomic information, education levels of adults and children are not significantly different between the treatment and comparison populations in this preprogram period.

From the reproductive histories of individual women in the 1996 MHSS $(n=5379)$ the average program treatment effect on fertility is found to be significantly negative for all age groups of women less than 55 in 1996, women who in 1977 when the program started were less than age 37 and hence still likely to have more children. The program's effects on fertility are clearly not homogeneous across woman of different birth cohorts, and interactions between 11 age dummies and treatment are therefore included in the reduced-form estimates of the program's effect on fertility and also in estimating the program effects on other family lifecycle outcomes. This heterogeneity in response to the program by mother's age may explain why Sinha's (2005) estimates of program cross effects differ from this subsequent study, and her focus on current enrollment rather than years of schooling completed may explain the lack of quantity-quality tradeoff.

Including controls in the reduced form fertility model for exogenous characteristics of the woman, her husband, household, and community infrastructure, the program treatment and interaction effects on the number of children ever born by women age 25 to 55 in 1996 are approximately one fewer child. The mother's health and nutrition, measured by her body mass index, is one unit higher in the treatment than in comparison areas. Her wage earnings or total income are significantly greater in the treatment areas among better educated women, even though the program's effect reducing fertility does not differ between women of different education levels.

${ }^{26}$ By 1996 the total fertility rate had declined by half in the comparison areas from 6 to 7 children per woman to about 3.5 children. The lack of convergence in fertility between the treatment and comparison areas after nearly two decades of program operation suggests the program provides more than a one-time improvement in information about new birth control and health technologies. Modest amounts of diffusion in the effective use of birth control techniques is documented in comparison villages which have boundaries with the treatment villages but this diffusion does not extend to use of preventive health inputs or other family life cycle consequences (Joshi and Schultz, 2007). See also Munshi and Myaux, 2006. 
Access to drinking and bathing/cleaning water sources within the extended family compound is greater in treatment areas by 1996, which should save women's time who are customarily responsible for fetching water, preparing food, and attending to family hygiene. The households of older and better educated women have higher total value of assets, specifically assets in the form of farmland, housing, ponds and orchards, jewelry and savings, if they reside in a program areas. This pattern is consistent with hypothesis 2 in section 4 that life cycle savings in the form of physical assets is a substitute for children, and consequently the program's effect reducing fertility facilitates household to accumulate more household assets by 1996 .

Finally, intergenerational effects of the outreach population program in Matlab are estimated. Child mortality before age 5 is a quarter less in program areas, but $\mathrm{Z}$ scores of the height and weight of children do not appear to improve, although the body mass index for daughters age 1 to 14 is greater in the treatment areas. Years of schooling of the woman's children, measured as a age-normalized $Z$ score, are significantly greater for sons age 9-14 and 15-29, but the effects are smaller in magnitude for daughters and not statistically significant. ${ }^{27}$

The cumulative effect of the Matlab program's outreach effort to subsidize the adoption and use of birth control and child and maternal health inputs is associated with relatively large declines in fertility and child mortality, improvements in the health and nutrition of women and daughters, and educational gains for children, but these are only significant for boys. A puzzle in these findings is why the program's long-term effects on women's earnings and household assets are concentrated among better educated women. The avoidance of an unwanted birth contribute to women's market productivity and asset positions, but only among the better educated strata of society. Why would the welfare gains of reduced childbearing not translate into economic benefit for the less educated women as well? The limited labor market opportunities for less educated women is one possible explanations for this puzzle, due to the structure of development increasing the local demand for only better educated female labor. Alternatively, cultural restrictions on married women's geographic mobility imposed by purdah in this traditional Muslim rural area of Bangladesh is another possible explanation, arising from the household supply side. The study does not determine the reason for why the Matlab program should be associated after roughly two decades with increased economic inequality by educational strata.

Half a century of experience with implementing family planning programs throughout the world has produced few experimental evaluation studies which document the long-term

${ }^{27}$ Second-stage estimates of fertility cross effects on these various family outcomes under the strong assumption that the program induced changes in fertility transmits all of the program effects on other family outcomes (Joshi and Schultz, 2007, Table 11). Were this valid, the reported IV estimates of fertility's effect identified by these program treatment variables provide additional evidence on the cross effects of exogenous fertility changes on family outcomes which are consistent with the reduced form reported here for mother's BMI, household assets and water sources, and son's schooling. The program started as a focused family planning program, but grew over time to extend more child and maternal health services and thus the IV estimates are also likely to capture the effect of parallel improvements in child and maternal health. 
consequences of family planning programs on family welfare. Estimating even the effect of programs on completed fertility of cohorts are rare and instead comparisons of adoption rates of new contraceptive methods or short run period birth rates are reported, few of which are experimentally designed, or statistically matched using propensity score methods or other satisfactory evaluation methods.

Other economic and demographic conditions that are hypothesized to have contributed to the transition decline in fertility include (1) improved child health and survival and diminished child malnutrition which are associated with increased supplies of calories per capita (Schultz, 1997) and improved public health programs for children and mothers; (2) increased educational attainment of females relative to males; and (3) improved employment opportunities for women, especially those outside of the family, which may empower women and are less readily combined with a mother's performance of child care (Schultz, 1994, 1997, 2002). In the following sections 5.12 and 5.13, a few studies are reviewed that estimate how public policies or instrumental variables account for variation in child health and parent education, respectively, and may thereby indirectly indirectly account for the reduction in fertility and the welfare of woman and their families.

\subsection{Health Effects on Fertility and Family Well Being}

Improvement in health and declines in mortality has benefitted families and the benefit can be viewed as a reduction in price of children which would, other things equal, increase the demand for children. The many-fold increase in world population since the onset of the Industrial Revolution is a result of the decline in age-specific mortality rates that has led to a doubling of the expectation of life at birth. This increase in survival rates occurred slowly at all ages until the end of the $19^{\text {th }}$ century, when survival rates increased more for infants and young children than at later ages. After the Second World War improvements in drugs and public health methods diffused rapidly to many low-income countries and very high levels of child mortality declined sharply (Schultz, 1969). If parents defined their reproductive goals in terms of having a specific number of surviving children to work with parents as adolescents and to care for elderly parents, and child loss was large fraction of the cost of parents producing a surviving child, price inelastic demand of parents for surviving children could account for birth rates declining in response to the drop in child mortality, and possibly to a homeostatic adjustment of fertility by parents to mortality which would dampen or prevent an acceleration in population growth. ${ }^{28}$

${ }^{28}$ Studies of household surveys have generally documented the positive association between a woman's child mortality rate and her fertility rate (e.g. Schultz, 1969, 1973, 1981). But this empirical regularity should be interpreted with caution as evidence of a replacement response of parents to the experience of child loss, because other factors are probably contributing to both the decline in child mortality and fertility. Lacking a valid exogenous basis for identifying this cross-effect of child mortality on fertility, only reduced-form equations can be estimated for both fertility and child mortality rates. Where there exists a clear empirical basis for identifying cross-effects, they may be tentatively estimated, and they suggest substantial positive responses of fertility to child survival in low income countries (Rosenzweig and Schultz, 1982; Schultz, 1969, 1997; Benefo and Schultz, 1996). 
Early child mortality and health of pregnant women, often proxied by the birthweight of their child, are correlated in clinical and epidemiological samples with the incidence of chronic illnesses and death in middle and late age, often related to cadiovascular and lung diseases (Barker, 1997). Historical samples (Fogel, 2004) also link in a wide range of settings improvements in nutrition and health of the mother and her community around the time of birth, childhood nutrition, and reduced exposure of early infectious diseases to improved adult health status, reduced chronic health problems after a individual reaches age 50, and increased years of disability-free life in old age, controlling in some cases for later socioeconomic status ( Kannisto, et al. 1994; Finch and Crimmins, 2004; Gluckman and Hanson, 2006). Conditions that achieved the reduction in child mortality and improvement in early child nutrition may have also physically and cognitively facilitated the child's achievement in school and enhanced their productivity as adult workers, but some evidence indicates the effects of early childhood investments seem to exceed what can be attributed to forms of observable human capital acquired later in life (Glewwe et al. 2001; Schultz, 2001; Cunha and Heckman, 2007). As in the case of evaluating family planning, however, researchers have rarely been able to identify with confidence the contribution to this general advance in child health of specific public health policy interventions. Without knowing the consequences of providing particular health interventions for specific groups, the general allocation of public resources to public health may be inefficient and fail to achieve economic and social development or improve social welfare.

The impact of fertility on family members requires careful empirical assessment. This paper has surveyed the evidence on exogenous sources of fertility to assess the likely impact of exogenous population policy on long run family outcomes. Although I have only outlined the conditions under which these estimates are satisfactory, more formal models characterize how estimates differ. ${ }^{29}$ Because the behavioral and biological mechanisms involved cut across disciplines, research in demography, sociology, public health, psychology and clinical sciences may all be relevant. Additional research is undoubtedly relevant and omitted here due to my lack of familiarity with these allied fields. Different forms of survey and experimental data, including qualitative research, may contribute to the generation of new hypotheses. One factor common to most efforts to understand fertility and health outcomes is parent education. Education may affect their productivity and hence the shadow price of their time in family production activities such as child training as well as in market production activities. Capacity to innovate and to use more efficiently new production techniques may also be linked to adult education, including their adoption and effective use of health care inputs and birth control (Schultz, 1992). Mother's health and education may also transfer inter-generational advantages to her children, and parents may be matched through marriage on these advantageous characteristics to their spouse, making more difficult any attribution of causal effects (Behrman and Rosenzweig, 2002; Behrman et al.,1997). Therefore, parents education is being reappraised in some studies as an endogenous determinant of child development, potentially associated with unobserved characteristics of the marriage match,

${ }^{29}$ See Rosenzweig and Wolpin (2000) and especially their last section which discusses estimates of the effect of fertility on mother's labor supply, of Cunha and Heckman (2007) where dynamic complementarities in various early childhood inputs to skill formation and labor productivity is hypothesized in various scientific disciplines analyzing child development. 
genetic ability, transmitted from parent to child genetically as well as through the family's socioeconomic status and economic wealth and marriage markets (e.g. Scarr, 1978; Plug, 2004).

\subsection{Effects of Women's Education on Fertility and Family Well Being}

The effects of female and male education on fertility and child health are critical for understanding the demographic transition, just as they are for explaining changes in health and birth control practices (Schultz, 1981, 1997). Instrumental variable methods may be useful in exploring whether the associations between parents education and health and fertility are causal, or biased by unobserved heterogeneity, such as due to preferences or innate abilities that affect many facets of family behavior. As with the instrumental variable estimates of fertility, research on this topic is currently concentrated in high-income countries, although it may be extended to lowincome countries where the expansion of education has been more rapid and now measured in periodic censuses and surveys. A key question is whether policy-induced changes in the education of women exerts less of an effect on fertility and on family health outcomes than implied by the cross sectional correlation estimates, which assumes the education of men and women is exogenous to factors affecting fertility and health, or there is no bias due to omitted variables. The consequences of schooling on labor productivity have been analyzed for fifty years by social scientists who were initially skeptical that the correlation between schooling and wages is entirely a causal effect. The choice to go to school is a family and individual decision, possibly affected by many unobserved abilities, educational opportunities, and policies which could benefit different sub-populations and potentially bias the directly estimated relationships between parent education, fertility and other family outcomes.

Currie and Moretti (2003) report for the United States that if a junior college opens in the county in which a woman is born, this extra local educational opportunity is positively associated with her probability of attending college which appears to cause these 'treated' women on average to have improved health outcomes for themselves and their children.

The educational attainment of Indonesian men and women as observed in 1995 is related to a 1974 primary school-building program (INPRES) which may have occurred in the individual's birthplace (Duflo, 2001). Two decades later in 1995, the school-building-induced gain in education is associated with wage returns of the potential beneficiaries born in those regions. Breierova and Duflo (2004) extend the analysis to assess the program's impact on fertility and child mortality of parents who are better educated due to the program. They account first for the average of wife and husband schooling and then for the schooling difference between wife and husband, using as instruments the school building program in birthplace and the Indonesian difference in age of husbands and wives, and the interactions between the program and age differences between husband and wife. These predicted average and gender differences in education are then employed to account for the women's fertility and child mortality as of 1995 . The probability of having a child by age 15 is significantly reduced by the gender difference in education, whether estimated by OLS or IV methods. Where women's education is predicted to be greater relative to men child mortality is lower, other things equal. But the number of children ever born by age 25 is not associated with the IV gender difference in education, possibly because the better educated women will have fewer children than their less educated peers after age 25. Although the 1995 survey is not able to assess how the program's effects on gender differences in schooling affected completed 
fertility, the empirical strategy may be more informative when implemented with later surveys picking up the program affected women at a later point in their lifecycle.

Osili and Long (2004) analyze the 1999 Nigerian Demographic Health Survey (DHS) and estimate the effect of female education on fertility (by age 25) due to an Universal Primary Education(UPE) program implemented for the non-Western regions of Nigeria during the petroleum boom of 1976-81. Women born in 1970-75 and currently residing in a UPE area report 1.1 to 1.3 more years of schooling than did women of other cohorts and living in other areas (Table 2). For these women, exposure to the UPE program is associated with them having .91 to .83 fewer children before the age of 25, controlling for initial female enrollment rates in their area (Table 3). According to their difference in difference method by birth cohort and region, and by instrumental variables based on the same identifying variation in program exposure, they conclude that the UPE increased female schooling and thereby decreased fertility by age 25 by .11 and .24 births, for each additional year of female completed schooling. These estimates of the program's effect on fertility through its effect on schooling are larger than those estimated by regressing fertility on female schooling using ordinary least squares. The study notes that the IV estimate of education's effect on fertility by age 25 , when freed of omitted "ability" bias are larger than the OLS estimates, which is contrary to their expectation. One recognized limitation of the study is that without information in the DHS on where a woman lived when she was eligible to attend primary school, the estimates are based on a restricted sample of two-thirds of the women who report they have never moved (Appendix 1), introducing potentially a sample selection bias. ${ }^{30}$

Using educational program expansions to estimate the effect of both parents' education on family outcomes allows one to assess how policies affect the levels of education by gender and how this development works through the marriage market to affect couples over their life. It has been hypothesized that women who are better educated may be sought as wives by men because of their greater capacity to produce high quality children, among other reasons. The correlation between women's schooling and child quality could therefore reflect in part men's preferences for lower fertility and higher child quality (Behrman et al, 1997). The outcome of the marriage market and bargaining process cannot, to my knowledge, be forecasted without making further assumptions. A limitation of the instrumental variable approach designed to isolate how regional educational expansions impact household decision making is that the gender difference in

${ }^{30}$ If out-migrants are on average better educated than those who stayed in their birthplace (as widely observed Cf. Schultz, 1982), the estimation sample of non-movers will underrepresent better educated women in the same birth cohort from a region. The omitted outmigrants may also be expected to have fewer children than women from the same birthplace with the same education who did not migrate, because the cost of migration would tend to be larger for women with more children. The selection of the Nigerian estimation sample is likely to bias toward zero the estimated effect of the UPE on female education and on fertility, but additional information is needed to assess how the sample selection bias would affect the IV estimates of the effect of female schooling on fertility. 
schooling is likely to be related to the gender differences in age at marriage, and in fertility. ${ }^{31}$ IV estimation techniques may validly identify the effects of men's and women's program-induced education on fertility and on investments in child quality, only if the regional implementation of the program is independent of other factors determining these household behaviors (Rosenzweig and Wolpin, 1986).

\section{Tentative Conclusions and an Agenda for Research on Fertility and Development}

Fertility is thought to be an important determinant of the welfare of women, children, and men. Policies that help individuals reduce unwanted fertility are expected to improve the well being of their families and society. But there is relatively little empirical evidence of these connections from fertility to family well-being and to inter-generational welfare gains, traced out by distinct policy interventions. Associations do not clarify the underlying causal relationships which should be the foundation for program evaluations (Moffitt, 2005). It is difficult to evaluate the consequences of social welfare programs, such as family planning, which change complex forms of lifetime behavior with ramifications for many other family outcomes and arrangements over many years.

First, population policies tend to be national in scope, and they may respond in politically subtle ways to evolving private demands by the population for the program's services, as well as to the public's priorities. Therefore, program treatments vary across a population in a manner that is likely to be nonrandom, and complicate what would otherwise be a more straightforward statistical evaluation of the association between a program's treatment and outcome (Rosenzweig and Wolpin, 1986). The interpretation of non-experimental program expansions across regions and over time, as illustrated by Miller's (2004) study of Colombia, should be interpreted with caution, because the program expansions are likely to be targeted to populations with distinct private demands for the public service.

Second, different groups in society may respond differently to the same social welfare program treatment, and this implies that the spillover effects on family outcomes of a certain program-induced change in fertility may benefit different groups in society only "locally". The instrumental variable (IV) empirical strategy used to identify the causal effect of a policy on completed fertility is interpreted here as estimating Local Average Treatment Effects (LATE) (Imbens and Angrist, 1994). These IV LATE estimates may not be readily generalized, because of program and population heterogeneity (Heckman, 1997; Moffitt, 2005).

${ }^{31}$ A final example is noted from Norway, where the compulsory length of education increased during the $1960 \mathrm{~s}$, but the timing of the reforms was left to be determined by the municipal school districts (Black, et al, 2003). In this case, the IV estimates imply that policy induced changes in compulsory education of mothers are less likely to improve the schooling or "quality" of offspring, compared with the direct OLS association between mother's and child's schooling. The study does not instrument for the gender difference in schooling of the parents, probably because it is a weak instrument and the age gap between husbands and wives in Norway is smaller than in Indonesia. 
Third, the responsiveness of individual well-being to a policy-induced change in fertility of a specified magnitude will depend on how the policy is implemented (e.g. voluntary family planning or birth quotas) and on what "activities" are available to substitute for having fewer children, including investment in productive assets such as land, self employment opportunities, credit, and schooling. More specifically, do parents benefitting from a program and having fewer children decide (1) the mother who had been responsible for child care is now able to reallocate more of her time to more productive activities outside of the family, (2) their children now are able to obtain more schooling and get better nutrition and health care, and (3) to save more of their lifetime income in the form of physical capital to provide for their support in old age?

Based on the limited empirical studies reviewed in this paper, some answers begin to emerge. It should be emphasized, however, that many of the studies are not yet based on rural communities in low-income countries because of a shortage of data and a lack of consensus on how to model fertility and family decision making :

(1) About half of the direct association between fertility and a mother's market labor supply appears to be due to the causal effect of fertility as it is affected by observable exogenous variables, such as twins. Although maximizing women's productive opportunities is a social goal, there are too few studies assessing the productivity of women in the home and market to confirm whether women with fewer children are indeed more productive and inclined to allocate more of their time to the market labor force in poor agricultural economies.

(2) The trade-off between the quantity of children a woman bears and the quality of those children is viewed by many as a stylized fact, but this behavioral regularity may be more common in high-income urban societies than elsewhere. This inverse relationship between fertility and the average child human capital could be caused by unobserved heterogeneity in people's preferences and constraints, and may not indicate the theoretically hypothesized positive cross-substitution effect (Rosenzweig and Wolpin, 1980b). Therefore, fertility-reducing programs in predominantly rural low-income countries should be evaluated with the goal of assessing whether particular policies that help women control their reproduction and improve their health contribute to the welfare of their children. Joshi and Schultz's (2007) study of the Matlab, Bangladesh reconfirmed Sinha (2005) finding that this long term experiment in family planning reduced fertility by about one child. Joshi and Schultz (2007) find gains associated with the village family planning and health program in child survival and male schooling as well.

(3) The hypothesis that policy-induced fertility declines have contributed to increases in family savings rates is intuitively plausible, as is the life-cycle savings hypothesis. However, with the exception of evidence on household assets from a single 1996 Matlab survey that suggest fertility declines are associated with increased ownership of a variety of assets, and no empirical evidence is known at the family level to test the hypothesis that exogenous fertility declines have increased household savings and the lifetime accumulation of physical wealth, which would be consistent the parent savings and fertility being substitutes over the lifecycle.

Most of the studies reviewed in this paper find that exogenous sources of fertility variation exert an absolutely smaller effect on a mother's market labor supply and on her children's health and schooling than is observed in raw cross sectional data. Instrumental variable estimates based 
on quasi-natural experiments are not a perfect substitute for a well-run policy experiment, such as implemented in Matlab. But well specified IV estimates can provide an initial approximation of the magnitude of the long-term consequences of population programs on female labor supply and investments in the human capital of children, two important sources of modern economic growth (Young, 1995). In the single case study where the impact of an intensive family planning program involving frequent home visits in a rural low-income community can be followed for 20 years, the accumulating evidence suggests that the program had a substantial and persistent effect reducing fertility by one child, reducing child mortality by a quarter, and raising schooling (Joshi and Schultz, 2007).

The challenge is to extend rigorous assessments of which population programs reduce fertility and improve family outcomes in a cost-effective way and distribute their benefits toward the least advantaged individuals, generally the rural poor. Program objectives should be defined in terms of long run family outcomes associated initially with declines in fertility and child mortality. With the passage of time, migration and adult earnings capacities of the mother may be expected to increase in response to the program, and difficult to measure improvements in health may emerge clearly for the mother and her children. To assess the effect of population policies on household savings will probably require better asset data from household panel surveys than are available currently, which will involve measuring before and after a program's implementation how all forms of marketable wealth change, including homes, consumer durables, land, business capital, financial assets, and jewelry. Moreover, these outcomes are likely to have a bearing on the way in which individuals form families and combine themselves into households. Normalizing the income or wealth of households for composition of members may introduce other sources of misleading bias because they are endogenous, as in studies of orphans in Africa. Households also share resources with extended family members and strategically rely on kinship networks, thus sustaining these private institutions to manage risk, provide insurance, and create what might be called social capital. Dealing appropriately with these complex behavioral issues opens an extensive agenda for microeconomic research on the family. The research will progress more rapidly if researchers share a common conceptual framework for analyzing these questions and translate that shared framework into a consistent statistical approach for describing how policies change family behavior and thereby achieve desired economic and social development. This framework at a minimum must recognize fertility as a family choice variable, and thus incorporate fertility and its long run consequences into behavioral models. To progress in this research household panel surveys will be especially valuable, and need to be designed to evaluate the role of population programs in the poorer parts of the world where today access to birth control and child and maternal health services are most limited. 


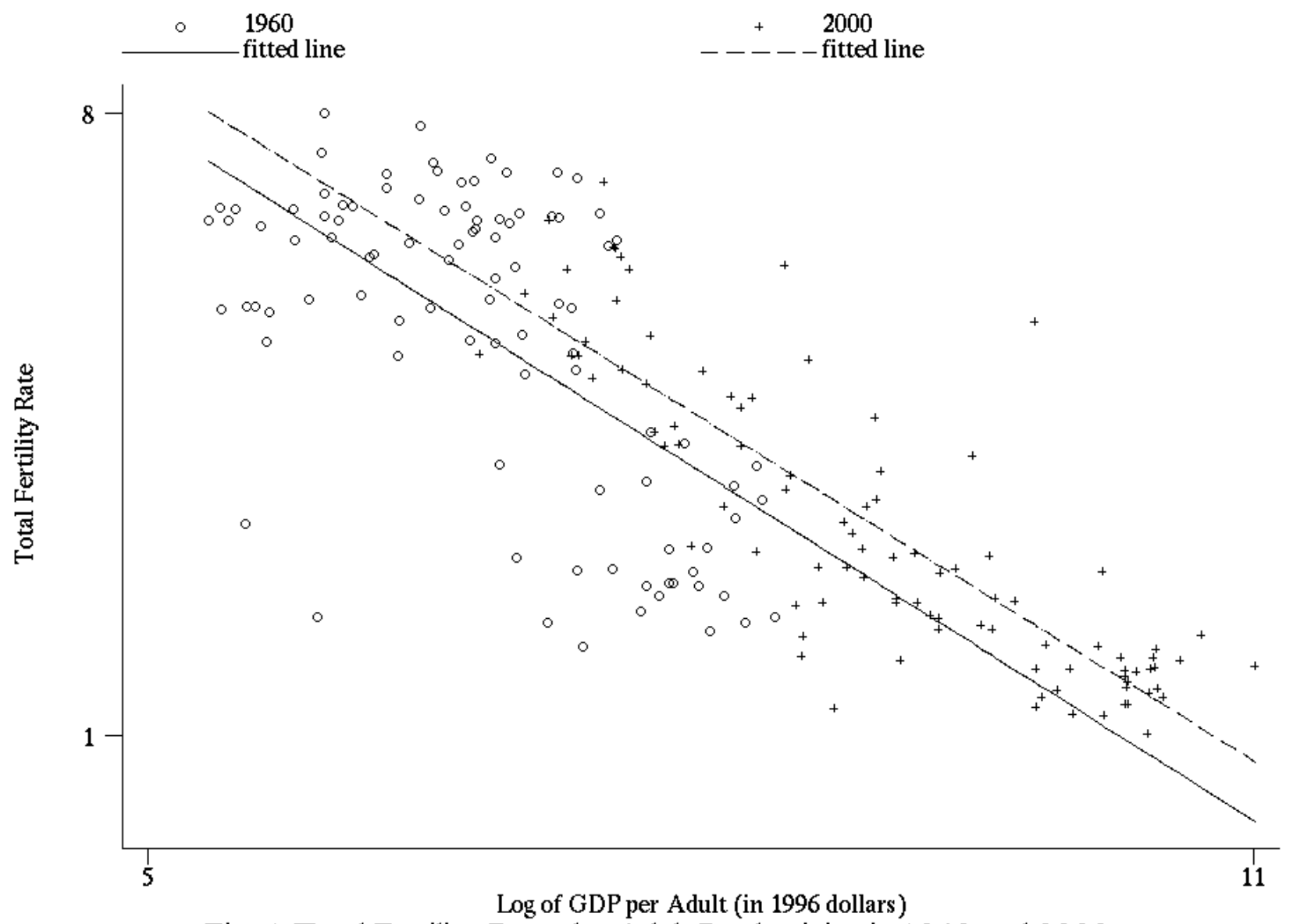

Fig. 1 Total Fertility Rates by Adult Productivity in 1960 and 2000

Source: United Nations 2003, World Bank development data base. Income per person age 15 or over in 1996 US real dollars, converted to purchasing power parity. Maximum sample of the same 95 countries for which data are available in both years. 


\section{Table 1: Family Behaviors and Outcomes Likely to be Affected by Exogenous Decline in Fertility}

I. Human capital formation

A. Mother's health improves with fewer and better-timed births, especially in her later years

B. Mother's market wage rises as her training through experience in the labor market increases

C. Child's health improvements may eventually be documented along many dimensions

(I) Infant survival and survival until age five increases

(ii) Weight at birth by sex increases

(iii) Height for age and sex increases, especially under age 5

(iv) Weight-for-height (Body Mass Index) by age and sex increases

(v) Age of menarche decreases

(vi) Inputs to produce health increase, such as expenditures on preventive health

D. Child's schooling increases along many dimensions

(I) Age of entry into school system

(ii) Repetition of school years reduced because of failure to matriculate

(iii) Current enrollment, given age and sex

(iv) Graduated from specific levels of the school system

(v) Final year of schooling completed among older children

(vi) Children's years of schooling completed at younger ages, normalized as a Z score by the population distribution of schooling by age and sex

(vii) Inputs to produce education increase, such as expenditures, student time on homework, or parent home time facilitating child education

E. Child's migration from parent residential community

(I) To find better employment

(ii) To marry and reside with spouse's family in order to reduce extended family risks

F. Delay of child's age at marriage

II Family labor supply or time allocation

A. Mother's market labor supply within and outside of the family increases

B. Children's labor supply may decrease

C. Father's labor supply may respond positively in short run and may later decrease with wealth gains

III Saving rate of parents increase to accumulate physical wealth for production and retirement

A. Because savings is measured only at the household level, it is difficult to attribute savings between generations in a multi-generational household or even extended family

B. Sample selection bias in estimating savings for young and old, concealing life cycle variation

IV. Transfers of cash, goods, and time to and from household members
A. From parents to their children
B. From children to their parents
C. Among other relatives in extended family or clan
D. From the state to support the vulnerable: young, old and disabled

V. Household Living Arrangements

A. Household formation 
(I) Marriage or cohabitation or visiting relationships

(ii) Partition as sons and daughters and brothers of household head leave to establish own household or join the family of their spouse

(iii) Migration to improve economic opportunities and reduce family pooled risks

B. Household partition because of death or ill health of head, e.g. placement of orphans

C. Female heads of household

(I) Because of widowhood

(ii) Because of divorce or permanent separation

(iii) Because of temporary migration of husband who transfers support and remains de facto head 
Table 2: Mechanisms by which Population Policy may Influence Family Behavior and Fertility

I. Subsidize home productive inputs or activities

A. Subsidize the diffusion of knowledge or best practice reproductive technological opportunities, through sex education in schools, family planning in health clinics and outreach programs, STD clinics, HIV testing and counseling

B. Subsidize the cost of adoption of new technology, i.e. new methods of family planning

C. Subsidize the continuing use of family planning by lowering user monetary and time costs

D. Provide lower cost and lower risk options for male and female sterilization

E. Increase access to emergency contraception, menstrual regulation, and safer and lower cost abortion

II. Provide local public health care for preventive and curative purposes

A. Prenatal care and tetanus vaccination of mother

B. Assistance with child birth

C. Monitoring early child growth and provide oral dehydration therapy for diarrhea

D. Childhood vaccinations

E. Protocols to identify health crises and securing appropriate treatment

III. Cash transfers to families conditional on their investments in child human capital
A. Food and nutritional supplements targeted to the poor and malnourished
B. School enrollment of girls and boys at critical transitions in school system
C. Discourage early marriage among girls
D. Discourage child labor in unhealthy and dangerous occupations

IV Strengthen the property rights and bargaining empowerment of women
A. Define and enforce property rights of women in productive assets and wealth
B. Establish and enforce rights to inheritance of women
C. Codify settlement patterns for women in divorce and regarding child custody
D. Facilitate information and legal protection for migrants to change residences
E. Discourage dowries or secure mechanisms whereby dowries become the property of the woman, in the event that the marriage ends or husband dies
F. Discourage polygyny

V. Rationing of births as in China's one-child policy : involuntary population policy
A. No compensating subsidy payment made to encourage fertility compliance, and penalties for out-of-plan births often regressive
B. With uniform rations for children, the costs of compliance are born primarily by those who want the most children, e.g. poorly educated, rural women
C. Reproductively rationed women confront incentives to consume more substitutes for children, for which the cross-price effects are positive, although wealth effects are negative 


\section{References}

Akresh, Richard, 2004, “Adjusting Household Structures: School Enrollment Impacts of Child Fostering in Burkina Faso”, Economic Growth Center discussion paper 897, Yale University, New Haven CT, November.

Angrist, J. and W. Evans, 1998, "Children and Their Parent's Labor Supply: Evidence from Exogenous Variation in Family Size”, American Economic Review, 88(3):450-477.

Angrist, J., V. Lavy, and A. Schlosser, 2006, "Multiple experiments for the causal link between the quantity and quality of children", working paper 06-26, MIT, Cambridge MA.

Arends-Kuenning, Mary and Sajeda Amin, 2004, "School Incentive Programs and Children's Activities: The Case of Bangladesh", Comparative Education Review, 48(3): 295-317.

Barker, D.J.P., 2001, (Ed.) Fetal Origins of Cardiovascular and Lung Disease, Dekker, New York.

Becker, G. S., 1960, “An Economic Analysis of Fertility”, in Demographic and Economic Change in Developed Countries, Princeton, N.J.: National Bureau of Economic Research.

Becker, G. S., 1981, A Treatise on The Family, Cambridge: Harvard University Press.

Becker, G. S. and H. G. Lewis, 1974, "Interaction between Quantity and Quality of Children”, in T. W. Schultz (ed.) The Economics of the Family, Chicago: University of Chicago Press.

Becker, G.S. and Nigel Tomes, 1976, "Child endowments and quantity and quality of children”, 84(2): S143162.

Behrman, J.B., A. Foster, and M. R. Rosenzweig, 1997, "Women's Schooling, Home Teaching, and economic Growth", Journal of Political Economy, 107: 632-714.

Behrman, J.B. and M. R. Rosenzweig, 2002, "Does increasing women's schooling raise the schooling of the next generation?", American Economic Review, 92(2): 323-334.

Ben Porath, Yorum, 1976, "Fertility Response to Child Mortality: Micro data from Israel”, Journal of Political Economy, 84 (4, part 2): S163-78.

Benefo Kofi and T. P. Schultz, 1996, "Fertility and Child Mortality in Cote D'Ivoire and Ghana", World Bank Economic Review, 10(1): 123-158.

Bengtsson, Tommy, et al. 2004, Life under Pressure: Mortality and Living Standards in Europe and Asia, 1700-1900, MIT Press: Cambridge MA

Blake, Judith, 1989, Family Size and Achievement, Berkeley and Los Angeles: University of California Press. 
Black, Sandra E., P. Devereux, and Kjell Salvanes, 2005a, “Why The Apple Doesn't Fall Far: understanding intergenerational transmission of human capital”, American Economic Review, 95(1): 437-449.

Black, Sandra E., P. Devereux, and Kjell Salvanes, 2005b, "The More the Merrier? The Effect of Family Composition on Children's Education", Quarterly Journal of Economics, 120(2): 669-700.

Bloom, David and J. Williamson, 1998, "Demographic Transition and economic miracles in emerging Asia", World Bank Economic Review, 12(3): 419-55

Breierova, Lucia and E. Duflo, 2004, "The Impact of Education on Fertility and Child Mortality: Do Father's Really Matter Less Than Mothers?”, National Bureau of Economic Research, Working Paper No. 10513, Cambridge, MA.

Bronars, S. G. and J. Groggers, 1994, "The Economic Consequences of Unwed Motherhood: Using Twin Births as a Natural Experiment”, American Economic Review, 84(6): 1141-1156.

Browning, Martin , 1992, "Children and household economic behavior". Journal of Economic Literature, 30(3): 1434-1475.

Browning, M. and P. A. Chiappori, 1998, "Efficient intrahousehold allocations: a generalized characterization and empirical test", Econometrica, 66 (6): 1241-1278.

Chiappori, P.A., 1992, “Collective labor supply and welfare” Journal of Political Economy, 100(3): 437-467.

Chun, Hyunbae and J. Oh, 2002, “An Instrument Variable Estimate of the Effect of Fertility on the Labor Force Participation of Married Women”, Applied Economics Letters, 9(10): 631-634.

Coale, Ansley and E. Hoover, 1958, Population Growth and Economic Development in Low Income Countries, Princeton University Press, Princeton NJ.

Cunha, Flavio and J. J. Heckman, 2007, “The Technology of Skill Formation”, IZA Discussion Paper no 2350, Institute for study of labor, Bonn Germany.

Currie, J. and E. Moretti, 2003, "Mother's Education and the Intergenerational Transmission of Human Capital: Evidence from College Openings" Quarterly Journal of Economics, 118(4): 1495-1532.

Dawkins, Richard, 1976, The Selfish Gene, Oxford University Press, Oxford UK.

Deaton, A., 1997, The Analysis of Household Surveys, Baltimore, MD: John's Hopkins University Press, (pp. 80-85).

Deaton, A. and C.H. Paxson , 1997, “ The Effects of Economic and Population Growth on National Savings and Inequality”, Demography, 34(1): 97-114.

Deolalikar, Anil and E. Rose, 1998, "Gender and Savings in Rural India”, Journal of Population Economics, 11(4): 453-470. 
Desai, Sonalde, 1995, "When are children from large families disadvantaged? Evidence from Cross National Analyses", Population Studies, 49(2): 195-210.

Donohue, J. J. and S. D. Levitt, 2001, "Legalized Abortion and Crime", Quarterly Journal of Economics, 116(2): 379-420.

Duflo, E., 2001, "Schooling and Labor Market Consequences of School Construction in Indonesia", American Economic Review, 91(4): 795-813.

Duraisamy P. and R. Malathy, 1981, "Impact of Public Programs on Fertility and Gender Specific Investments in Human Capital of Children in Rural India", (ed.) T. P. Schultz, Research in Population Economics, Vol. 7, Greenwich, CT: JAI Press.

Edlund, Lena, and N.-P. Lagerlof, 2006, "Individual vs. Parental consent in marriage: implications for intra household resource allocation and growth", American Economic Review, 96(2): 542-551.

Edmonds, Eric V, 2006, “Child Labor” this volume

Fauveau, Vincent (ed.), 1994, Women, Children and Health, ICDDR,B Special Publication No. 35, International Centre for Diarrhoeal Disease Research Bangladesh, Dhaka.

Field, Erica, 2003, "Fertility response to urban land titling programs: the role of ownership security and the distribution of household assets", unpublished paper, Harvard University.

Field, Erica, and A. Ambrus, 2005, "Early Marriage and Female Education in Bangladesh", unpublished paper Harvard<efield@latte.harvard.edu $>$.

Finch, C. E. and E. M. Crimmins, 2004, "Inflammatory Exposure and Historical Changes in Human LifeSpans", Science, 305: 1736-1739.

Fogel, R. W., 2004, The Escape from Hunger and Premature Death, 1700-2100, Cambridge University Press, New York.

Foster, A. D., 1998, “Altruism, Household Coresidence, and Women's Health Investments in Bangladesh”, unpublished, Brown University, Providence, RI.

Foster, A..D.and N. Roy, 1997, "The Dynamics of education and fertility: evidence from a family planning experiment", processed, Brown University, Providence RI.

Freedman, R. and J. Y. Takeshita, 1969, Family Planning in Taiwan: An Experiment in Social Change, Princeton, NJ: Princeton University Press.

Gertler, P. J. and J. W. Molyneaux, 1994, "How Economic Development and Family Planning Programs Combined to Reduce Indonesian Fertility”, Demography, 31(1): 33-63. 
Glewwe, Paul, H.G. Jacoby and E.M.King, 2001, "Early Childhood Nutrition and academic achievement: a longitudinal analysis", Journal of Public Economics, 81: 345-368.

Gluckman, Peter and M. Hanson (eds.), 2006, Developmental origins of health and disease, Cambridge University Press, Cambridge UK.

Goldin, Claudia, 1990, Understanding the Gender Gap, New York: Oxford University Press.

Guinanne, Timothy W., 1997, The Vanishing Irish: Household Migration and the rural Economy in Ireland, 1850-1914. Princeton University Press, Princeton NJ.

Gruber, Jonathun,. P.B. Levine, and D. Staiger, 1999, “Abortion legalization and child living circumstances: who is the marginal child", Quarterly Journal of Economics, 114(1): 263-291.

Haddad, L., J. Hoddinott, and H. Alderman, 1997, Intra Household Resource Allocation in Developing Countries, Baltimore, MD: Johns Hopkins University Press.

Hammer, J. S., 1986, “Children and Savings in Less Developed Countries,” Journal of Development Economics, 23: 107-118.

Hamoudi, Amar and D. Thomas, 2005, "Pension income and the well being of children and grandchildren: new evidence from South Africa", economics department UCLA..

Hanushek, E.A., 1992, “The Trade-off between Child Quantity and Quality”, Journal of Political Economy, 100(1): 84-117.

Heckman, J. J. , 1974, “Shadow Prices, Market Wages and Labor Supply”, Econometrica, 42(1): 679-94.

Heckman, J. J., 1997, "Instrumental Variables: A Study of Implicit Behavioral Assumptions Used in Making Program Evaluations", Journal of Human Resources, 32(2): 441-462.

Heckman, J. J. and J. R. Walker, 1991, "Economic models of fertility dynamics: a study of Swedish fertility", in Research in Population Economics, Vol. 7, (ed.) T. P. Schultz, JAI Press Inc., Greenwich CT.

Hotz, V. Joseph, J. A. Klerman, and R.J. Willis, 1997, "The Economics of Fertility in Developed Countries", in Handbook of Population and Family Economics, (eds.) M. R. Rosenzweig and O. Stark, North Holland Publishers: Amsterdam.

Hussein, S., 1989, "Effect of Public Programs on Family Size, Child Education, and Health”, Journal of Development Economic, 30: 145-158.

Iacovou, Maria, 2001, "Fertility and Female Labour Force Participation", IS. discussion paper, University of Essex, Colchester, UK.

Imbens, G. W. and J. D. Angrist, 1994, "Identification and Estimation of Local Average Treatment Effects", Econometrica, 62(2): 467-476. 
Jacobsen, J. P., J. W. Pearce III, J. Rosenbloom, 1999, “The Effects of Childbearing on Married Women's Labor Supply and Earnings”, Journal of Human Resources, 34(3): 449-474.

Jensen, Robert, 2005, "Equal Treatment, unequal outcomes? Generating gender inequality through fertility behavior", J. F. Kennedy School of Government, Harvard University, Cambridge MA.

Johnson, D. G., 1999, “Population and Development”, China Economic Review, 10(1): 1-16.

Joshi, Shareen, 2004, "Female Household-Headship in Rural Bangladesh: Incidence, Determinants, and Impact of Children's Schooling”, Economic Growth Center Discussion Paper No 894, Yale University, New Haven, CT, September.

Joshi, Shareen. and T. P. Schultz, 2007, "Family Planning as an investment in development: evaluation of a program's consequences in Matlab, Bangladesh," Economic Growth Center Discussion Paper 951, Yale University, New Haven CT.

Killingsworth, Mark, 1983, Labor Supply, Cambridge, Cambridge University Press.

Kim, Jungho and A. Aassve, 2006, "Fertility and its consequences on family labour supply", IZA discussion paper no. 2162, Bonn Germany.

Koenig, M.A., U. Rob, M.A. Kahn, J. Chakroborty, and V. Fauveau, 1992, "Contraceptive use in Matlab. Bangladesh in 1990: levels, trends and explanations”, Studies in Family Planning, 23(6): 352-364.

Ksoll, Christopher, 2007,"Family Networks and orphan caretaking in Tanzania”, unpublished paper, Yale University.

Kuznets, S., 1966, Modern Economic Growth : Rate, Structure and Spread, Yale University Press, New Haven CT.

Lam, David and S. Duryea, 1999, "Effects of schooling on fertility, labor supply and investment in children, with evidence from Brazil”, Journal of Human Resources, 34(1): 160-192.

Lee, Jungmin, 2004, “Sibling Size and Investment in Children's Education: An Asian Instrument”, IZA discussion paper 1323, Bonn, Germany $<\underline{\text { iza@,iza.org }>.}$

Lee, R. D. , 1973, "Populaton in Preindustrial England: An Econometric Analysis", Quarterly Journal of Economics, 84(4): 581-607.

Li, Xia, 2005, "Impact of Childbearing on Women's Labor Market Outcome: Using New Data and Methods", unpublished, Ph.D. draft, Yale University, New Haven, CT.

Lloyd, C.B., 1994, "Investing in the next generation: the implications of high fertility at the level of the family", in R. Cassan (ed.) Population and Development: Old debate, new conclusions, Washington D.C.: Overseas Development Council. 
Lloyd, C.B.(ed.), 2005, Growing up Global: The Changing Transitions to Adulthood in Developing Countries, National Research Council and Institutes of Medicine, Washington D.C.: National Academies Press.

Maluccio, J. , D. Thomas, and L. Haddad, 2003, "Household Structure and Child Well Being: Evidence from KwalaZulu-Natal", in A. Quisumbing, (ed.), Household Decisions, Gender, and Development: A Synthesis of Recent Research, IFPRI and Johns Hopkins University Press, Baltimore MD. Pp. 131130 .

Maralani, Vida, 2004, "Family Size and Educational Attainment in Indonesia: A Cohort Perspective", UCLA, paper presented at The Population Association of America meetings, Boston MA, April 1-3, 2004.

McElroy, Marjorie and M.J.Horney, 1981, "Nash-Bargained Household Decisions: Toward a Generalization of the Theory of Demand", International Economic Review, 22(2) 333-350.

Miller, Grant, 2004, “Contraception as Development? New Evidence from Family Planning in Colombia”, Harvard University graduate student working paper, November, Cambridge MA.

Mincer, J. ,1962, "Labor Force Participation of Married Women”, in Aspects of Labor Economics, (ed.) H. G. Lewis, Universities National Bureau Conference for No. 14, Princeton, NJ: Princeton University Press.

Mincer, J., 1963,"Market prices, opportunity costs and income effects"in : C. Christ et al. (Eds.) Measurement in Economics, Stanford University Press, Stanford CA.

Modigliani, Franco and R. Brumburg, 1954, "Utility Analysis and the Consumption Function," chapter 15 in Post-Keynesian Economics, (ed) K.K. Kurihara, Rutgers University Press: New Brunswick NJ, pp. 388-436.

Moffitt, Robert, 2005, "Remarks on the analysis of causal relationships in population research", Demography, 42(1): 91-108,

Montgomery M., A. Kouame, and R. Oliver, 1995, The Tradeoff between Number of Children and Child Schooling, Living Standards Measurement Study Working Paper No 112, The World Bank, Washington D. C.

Montgomery, M.R. and C.B. Lloyd, 1999, “Excess Fertility, Unintended Births, and Children’s Schooling”, in C. Bledsoe, J.B. Casterline, J.A. Johnson-Kuhn, and J.G. Haaga (eds), Critical Perspectives on Schooling and Fertility in the Developing World, National Research Council, Washington D.C., National Academies Press.

Munshi, K. and J. Myaux, 2006, "Norms and the Fertility Transition”, Journal of Development Economics, 80: $1-38$.

Morley S. and D. Coady, 2003, From Social Assistance to Social Development: Targeted Educational Subsidies in Developing Countries, Center for Global Development, Washington D. C. 
National Academy of Sciences, 1971, Rapid Population Growth, Baltimore, MD: John Hopkins University Press.

National Research Council, 1986, Population Growth and Economic Development: Policy Questions, Washington D. C.: National Academy Press.

Osili, U.O. and B.T. Long, 2004, "Does Female Schooling Reduce Fertility? Evidence from Nigeria”, Indiana University Purdue Indianapolis, Indianapolis, IN.

Oster, Emily ., 2005, "Hepatitus B and the Case of the Missing Women”, Journal of Political Economy, 113(6): 1163-1216.

Parker, Susan W, L. Rubalcava and G. Teruel , 2006,"Evaluating Conditional Schooling and health Programs: The case of Progresa", in this volume.

Phillips, J. F., R. Simmons, M. A. Koenig, and J. Chakraborty, 1988, "Determinants of Reproductive Change in a Traditional Society: Evidence from Matlab, Bangladesh", Studies in Family Planning, 19(6): 313334.

Phillips, J. F., W. Stinson, S. Bhatia, M. Rahman, and J. Chakraborty, 1982, "The Demographic impact of Family Planning - Health Services Project in Matlab, Bangladesh, Studies in Family Planning, 13(5): 131-140.

Pitt, M. and S. Khandkar, 1998, "The Impact of Group Based Credit Programs on Poor Households in Bangladesh” Does the Gender of Participants Matter?”, Journal of Political Economy, 106(5): 958996.

Plug, Erik, 2004, "Estimating the effects of mother's schooling on children's schooling using a sample of adoptees", American Economic Review, 94(1): 358-368.

Pollak, Robert A., 1969, "Conditional Demand Functions and Consumption Theory”, Quarterly Journal of Economics, 83(1): 60-78.

Qian, Nancy, 2006, "Quantity-Quality: The positive effect of family size on school enrollment in China", Economics Department, Brown University, Providence RI.

Quisumbing, A. R., J. P. Estudillo, and K. Otsuka, 2004, Land and Schooling: Transferring Wealth Across Generations, Johns Hopkins University Press, Baltimore, MD.

Quisumbing, A.R. and J.A. Maluccio, 2003, "Resources at Marriage and Intrahousehold Allocation: Evidence from Bangladesh, Ethiopia, Indonesia, and South Africa", Oxford Bulletin of Economics and Statistics, 65(3): 283-323.

Rahman, O., J. Menken, A. Foster and P. Gertler, 1999, "Matlab [Bangladesh] Health and Socioeconomic Survey (MHSS) ,1996, Inter-university Consortium for Political and Social Research, Ann Arbor, Michigan (ICPSR 2705). 
Rose, Elaina, 2000, “Gender Bias, Credit Constraint and Time Allocation in Rural India”,Economic Journal, 110(465): 738-58.

Rosenzweig, M. R. and R. E. Evenson, 1977, "Fertility, Schooling and the Economic Contribution of Children in Rural India", Econometrica, 45(5): 1065-1079.

Rosenzweig, Mark R., 1990, "Population growth and human capital investments: theory and evidence", Journal of Political Economy, 98(5): S38-70.

Rosenzweig, M. R. and T. P. Schultz, 1982, "Child Mortality and Fertility in Colombia”, Health Policy and Education, 2: 305-348.

Rosenzweig, M. R. and T. P. Schultz, 1985, "The Demand and Supply of Births: Fertility and it's Life Cycle Consequences”, American Economic Review, 75:5 (December), pp 992-1015.

Rosenzweig, M. R. and T. P. Schultz, 1987, "Fertility and Investment in Human Capital in Malaysia”, Journal of Econometrics, 36:163-184.

Rosenzweig, M. R. and K. Wolpin, 1980a, “Testing the Quantity-Quality Fertility Model”, Econometrica, 48(1): $227-240$.

Rosenzweig, M. R., and K. I. Wolpin, 1980b, "Life Cycle Labor Supply and Fertility: Causal Inferences from Household Models", Journal of Political Economy, 88(2): 328-348.

Rosenzweig, M. R., and K. I. Wolpin, 1982, "Government Interventions and Household Behavior in a Developing Country”, Journal of Development Economics, 10: 209-226.

Rosenzweig, M. R. and K. Wolpin, 1985, "Specific Experience, Household Structure and Intergenerational Transfers: Farm Family Land and Labor Arrangements in Developing Countries", Quarterly Journal of Economics, 100(Supplement): 961-987.

Rosenzweig, M. R. and K. Wolpin, 1986, "Evaluating the Effects of Optimally Distributed Public Programs: Child Health and Family Planning Interventions", American Economic Review, 76(3): 470-482.

Rosenzweig, M. R., and K. I. Wolpin, 2000, "Natural 'Natural Experiments' in Economics”, Economic Literature, 38: 827-874.

Rosenzweig, M.R. and J. Zhang, 2006, “ Do Population control policy induce more human capital Investment? Twins, birthweight and China's one-child policy”, Economic Growth Center Discussion Paper 933, Yale University, New Haven CT.

Samuelson, P.A., 1958, “An exact consumption loan model of interest with or without the contrivance of money, Journal of Political Economy, 66(6): 467-482.

Scarr, S., 1978, "The influence of "family background" on intellectual attainment", American $\underline{\text { Sociological }}$ Review, 43(5): 674-692. 
Schultz, T. Paul., 1969, “An Economic Model of Family Planning and Fertility”, Journal of Political Economy, 77(2): 153-180.

Schultz, T. P., 1973, "Explanations of Birth Rate Changes over Space and Time: A Study of Taiwan”, Journal of Political Economy, 81(2, Pt.II) :S238-274.

Schultz, T. P., 1981, Economics of Population, Reading, MA: Addison-Wesley Publishers.

Schultz, T. P., 1988, "Heterogeneous Preferences and Migration: Self Selection, Regional Prices and Programs, and the Behavior of Migrants in Colombia", in Research in Population Economics, Vol. 6, Greenwich CT: JAI Press.

Schultz, T. P., 1992, “Assessing Family Planning Cost-Effectiveness" in Family Planning Programmes and Fertility, J. F. Phillips and J. A. Press, New York: Oxford University Press, 78-105.

Schultz, T. P. (ed.), 1995, Investment in Women's Human Capital, Chicago: University of Chicago Press.

Schultz, T. P., 1997, "The Demand for Children in Low-Income Countries", Family Economics, Vol 1A, Chapter 8, (eds.) M. R. Rosenzweig and O. Stark, Amsterdam: North Holland Pub. Co.

Schultz, T. P., 2001, "Women's Roles in the Agricultural Household: Bargaining and Human Capital Investments", in Agricultural and Resource Economics Handbook, (eds.) B. Gardner and G. Rausser, Amsterdam: Elsevier Publisher.

Schultz, T. P., 2002, "Fertility Transition: Economic Explanations", International Encyclopedia of the Social and Behavioral Sciences, (eds.) N. J. Smelser and P. B. Baltes, Pergamon, Oxford, pp 5578-5584.

Schultz, T. P.,2004a, "School Subsidies for the Poor: Evaluating the Mexican Progresa Poverty Program", Journal of Development Economics, 74:199-250.

Schultz, T. P., 2004b, "Demographic Determinants of Savings: Estimating and Interpreting Aggregate Associations in Asia", presented at $10^{\text {th }}$ Anniversary Conference of The China Center for Economic Research, Beijing, September 16-17, 2004. <www.iza.org Discussion Paper No. 1479.

Schultz, T.P., 2004c, "Human Resources in China: The Birth Quota, Returns to Education and Migration", Pacific Economic Review, 93(3): 245-267.

Schultz, T. P. and G. Mwabu, 2003, "The Causes and Consequences of Fertility in Contemporary Kenya", Economic Growth Center unpublished paper, Yale University, New Haven, CT.

Schultz, T. P. and Zeng Yi, 1995"Fertility in Rural China", Journal of Population Economics, 8: 329-350.

Schultz, T. W., 1974, Economics of the Family, University of Chicago, Chicago. 
Sinha, Nistha, 2005, "Fertility, Child Work, and Schooling Consequences of Family Planning Programs", Economic Development and Cultural Change, 54(1): 97-128.

Thomas, Duncan., 1990, "Intra-Household Resource Allocation: an Inferential Approach", Journal of Human Resources, 25(4): 635-664.

Thomas D., 1994, “Like Father, Like Son: Like Mother, Like Daughter”, Journal of Human Resources, 29(4): 950-989.

Tobin, James and H. S. Houthakker, 1950-51, "The Effects of Rationing on Demand Elasticities", Review of Economic Studies, 18: 140-153.

United Nations, 2003, World Population Prospects: the 2002 Revision, vol 1, Dept of Economic and Social Affairs, Population Division, New York: United Nations.

Willis, Robert J., 1974, “A new approach to the economic theory of fertility”, in Economics of the Family, (ed.) T. W. Schultz, University of Chicago, Chicago.

Wolpin, Kenneth .I., 1984, “An estimable dynamic stochastic model of fertility and child mortality" Journal of Political Economy, 92: 852-974.

Wolpin, K. I., 1997, "Determinants and Consequences of the mortality and health of infants and children", in Handbook of Population and Family Economics, (eds.) M.R. Rosenzweig and O. Stark, North Holland Pub Co: Amsterdam.

Young, Alwyn, 1995, "The Tyranny of Numbers: Confronting the Statistical Realities of the East Asian Growth Experience", Quarterly Journal of Economics, 110(3): 641-680.

Zajonc, R.B., 1976, "Family Configuration and Intelligence”, Science, vol 192, No. 4236: 227-236. 